\title{
A COLUMBITIZAÇÃO DO PIROCLORO DO ALBITA GRANITO NA MINA PITINGA (AM): RELAÇÕES COM A MINERALIZAÇÃO DE CRIOLITA
}

\author{
ORLANDO RENATO RIGON MINUZZI', ARTUR CEZAR BASTOS NETO², \\ VITOR PAULO PEREIRA ${ }^{2} \&$ LISANDRO NUNES ${ }^{2}$
}

\begin{abstract}
Resumo No depósito de Pitinga (Estado do Amazonas), o minério primário está associado à fácies albita granito do granito Madeira que contém um depósito de Sn de classe mundial e importantes reservas de Nb, Ta, ETR, Y e F (criolita). Este estudo investiga as relações entre as mineralizações de $\mathrm{Nb}$ e Ta (disseminada) e de criolita (disseminada e maciça) no entorno do depósito Criolítico Maciço. O U-Pb-pirocloro magmático foi afetado por columbitização caracterizada, num estágio inicial, pela perda de $\mathrm{Pb}$ e enriquecimento em $\mathrm{U}$ e $\mathrm{Nb}$, formando $\mathrm{Pb}-\mathrm{U}$-pirocloro e o U-pirocloro. $\mathrm{O}$ aumento na vacância do sítio $\mathrm{A}$ do pirocloro resultou em sua desestabilização e na formação de columbita, com assinaturas geoquímicas de Sn e U herdadas do pirocloro. No pirocloro, paralelamente ao empobrecimento em $\mathrm{Pb}$, ocorreu enriquecimento em $\mathrm{Ca}, \mathrm{F}$, $\mathrm{Ce}$ e Sn e empobrecimento em $\mathrm{Fe}$. $\mathrm{Na}$ zona de transição entre as subfácies albita granito de núcleo e de borda, ocorrem inversões nestas evoluções o que é interpretada como fruto da diminuição da atividade de flúor no fluido responsável pela columbitização. As relações espaciais entre a distribuição das variedades de pirocloro, columbita e o depósito Criolítico Maciço mostram que a columbitização foi promovida pelo mesmo fluido responsável pela mineralização criolítica, cujo aporte ascendente ocorreu pela zona central do albita granito. Gradientes geoquímicos ligados à perda de $\mathrm{F}$ do fluido, de caráter redutor, explicam as descontinuidades geoquímicas nos minerais estudados, assim como, provavelmente, algumas das diferenças entre as paragêneses das sufácies de núcleo e borda do albita granito. Os resultados fornecem importantes informações para lavra e beneficiamento do minério de $\mathrm{Nb}$ e $\mathrm{Ta}$.
\end{abstract}

Palavras-chaves: pirocloro, columbita, criolita, columbitização, albita granito.

\begin{abstract}
PYROCLORE COLUMBITIZATION IN ALBITE GRANITE AT PITINGA MINE (AM): RELATIONSHIP WITH CRYOLITE ORE GENESIS. At the Pitinga mine (Amazonas state) the primary ore is associated with the Madeira granite albite facies that contains a world class Sn deposit and a important Nb, Ta, ETR, Y and F (cryolite) reserves. This study show the relationships among disseminated $\mathrm{Nb} / \mathrm{Ta}$ ore cryolite (disseminated and massive) around the Cryolite Massive Deposit. The magmatic U-Pb-pyroclore was altereted by a fluid rich in fluorine. In an initial stage, $\mathrm{Pb}$ was lost and $\mathrm{U}$ and $\mathrm{Nb}$ were enriched resulting in $\mathrm{Pb}-\mathrm{U}$ and $\mathrm{U}$-pyroclores. This process promote an increasing in site $\mathrm{A}$ vacancy and the piroclore structure colapse and result in columbite formation. This mineral mantain the $\mathrm{Sn}$ and $\mathrm{U}$ geochemical signatures, that are inherited from pyroclore. The $\mathrm{Pb}$ impoverishment was followed by $\mathrm{Ca}, \mathrm{F}, \mathrm{Ce}$ and $\mathrm{Sn}$ relative enrichment and $\mathrm{Fe}$ impoverishment. These behavior change at the transition zone between the nucleus and border albite granite subfacies. It was interpreted as product of reduction on the fluorine activity, that promote the columbitization. Spatial relationships among pyroclore varieties and columbite distribution and Cryolite Massive Deposit permited verify that the columbitization process was promoted by the cryolite mineralizing fluid. Gradients linked to $\mathrm{F}$ on this fluid probably explains the geochemical descontinuities in the studied minerals, as well as some differences among the nucleus and border albite granite subfacies. Some implications on $\mathrm{Nb} / \mathrm{Ta}$ mining and recovering are also discussed.
\end{abstract}

Keywords: pyroclore, columbite, cryolite, columbitization, albite granite.

INTRODUÇÃO O distrito mineiro de Pitinga localiza-se no município de Presidente Figueiredo, no Estado do Amazonas (Figura 1). A produção mineral neste distrito foi iniciada em 1980 pela exploração da cassiterita em aluviões. Mais recentemente, a produção voltou-se para o minério primário associado ao granito Madeira que, além de conter um depósito de $\mathrm{Sn}$ de classe mundial, contém, também, importantes reservas de $\mathrm{Nb}$ e Ta, além de ETR, Y e F (criolita) que serão exploradas como subprodutos.

O granito Madeira e suas mineralizações têm algumas características muito incomuns. Por um lado, a afinidade peralcalina do granito Madeira não é favorável à mineralização de $\mathrm{Sn}$ e não existe modelo que explique, para rochas deste tipo, a associação do Sn com Nb e Ta. Por outro lado, com exceção da jazida de Ivigtut (Groenlândia), fechada em 1986, a de Pitinga é o único caso mundial de depósito de criolita passível de exploração econômica. O granito Madeira é mineralizado unicamente em sua parte central (Figura 2), na fácies albita granito $(\mathrm{AG})$, que é subdividida nas subfácies albita granito de borda (AGB) e albita granito de núcleo (AGN). Ambas são portadoras da mineralização de Sn. Entretanto, segundo Costi (2000), os demais minérios repartem-se distintamente nas duas subfácies.
No AGN, ocorrem um depósito criolítico maciço (DCM), minério disseminado de criolita e minério disseminado de $\mathrm{Nb}$ e Ta (unicamente pirocloro). No AGB, considerado resultante do autometassomatismo e forte oxidação do $\mathrm{AGN}$, a mineralização de $\mathrm{F}$ é representada por fluorita (subeconômica) e o minério de $\mathrm{Nb}$ e Ta é a columbita. Os minérios disseminados apresentam uma zonação vertical caracterizada pelo decréscimo dos teores em profundidade. Entretanto, suas curvas de isoteores aprofundam-se marcadamente na zona do DCM. Destaca-se, portanto, a necessidade de um estudo integrado das diferentes mineralizações para que se possa compreender a gênese do DCM e a própria evolução metalogenética do granito Madeira.

Neste trabalho são apresentados os primeiros resultados da investigação sobre a mineralização de $\mathrm{Nb}$ e Ta do granito Madeira. No estágio atual da pesquisa, foram estudadas principalmente amostras do DCM e da rocha encaixante mais próxima a este depósito e, para comparação, um número reduzido de amostras mais distais. Os resultados obtidos evidenciam um quadro muito mais complexo do que o até então conhecido na literatura sobre a mina de Pitinga. Identificou-se um pirocloro primário de composição rara (U-Pb-pirocloro), que foi afetado por alteração que conduziu à formação de diferentes variedades 


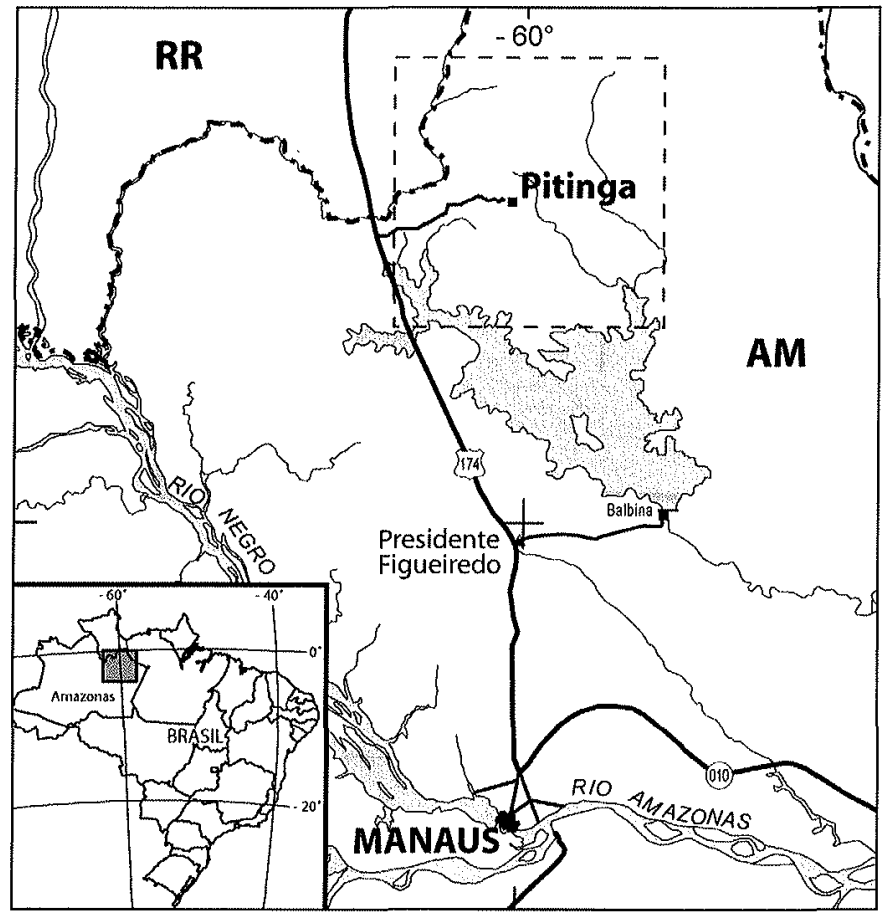

Figura 1: Mapa de localização da mina de Pitinga

de pirocloro e, num estágio final, à formação de columbita. Este mineral ocorre, portanto, também na subfácies de núcleo, além de apresentar importantes variações de composição conforme sua posição em relação ao DCM. Os presentes autores desconhecem outras descrições de transformações minerais sucessivas no processo de alteração pirocloro-columbita. Os resultados obtidos têm novas implicações para a evolução metalogenética do granito Madeira. Por outro lado, salientam-se as importantes implicações que as variações composicionais e zonações espaciais, identificadas no pirocloro e na columbita, têm para a lavra e beneficiamento do minério de Pitinga.

MATERIAIS E MÉTODOS A coleta de amostras no DCM e encaixante próxima foi efetuada a partir de 3 furos de sondagem (Fig. 3) que atravessam verticalmente o DCM. Para comparação, foram coletadas amostras mais distantes do DCM, utilizando-se o furo L3300/5350, que atravessa, do topo para a base, o AGB, uma zona transicional (aqui designada AGT) e atinge o $A G N$, e o furo $\mathrm{L} 450 \mathrm{~N} / \mathrm{F} 750 \mathrm{~W}$, que está inserido unicamente no AGN. As amostras de AGN destes dois furos distantes do DCM são designadas AGNEX.

As amostras foram estudadas na Universidade Federal do Rio Grande do Sul. Nas análises por microscopia eletrônica de varredura (MEV), utilizou-se aparelho marca JEOL, modelo JSM - 5800 , com energia de $20 \mathrm{kV}$, corrente de $25 \mathrm{nA}$ e tempo de contagem de 100 segundos. No caso de mapeamento de elementos, o tempo de aquisição foi de 50 minutos. As análises por microssonda elétrônica (MSE) foram efetuadas no aparelho marca CAMECA, modelo SX-50. Na primeira etapa de análises foi utilizada energia de $15 \mathrm{KeV}$, corrente de $10 \mathrm{nA}$, feixe de $1 \mu \mathrm{m}$, tempo de 20s. Especifica-se a seguir os cristais utilizados pelos espectrômetros, as radiações e os padrões utilizados para a dosagem dos elementos químicos: [TAP: ${ }^{-1} \mathrm{FK} \alpha\left(\mathrm{CaF}_{2}\right),{ }^{1} \mathrm{NaK} \alpha$ (JADE), ${ }^{4} \mathrm{SiK} \alpha$ (ANOR), ${ }^{5} \mathrm{TaM} \alpha$ (Ta)]; [LIF: ${ }^{2} \mathrm{FeK} \alpha(\mathrm{MnOH})$, ${ }^{3} \mathrm{LaL} \alpha$ (Ree3)]; [PET: 'K K $\alpha$ (ASBE), ${ }^{2} \mathrm{Ca} \mathrm{K \alpha}$ (ANOR), ${ }^{4} \mathrm{Ti}$ $\left.\mathrm{K} \alpha\left(\mathrm{TiO}_{2}\right),{ }^{3} \mathrm{Ce} \mathrm{L} \alpha(\mathrm{Ree} 3),{ }^{4} \mathrm{U} \mathrm{M} \alpha(\mathrm{xGLA}),{ }^{2} \mathrm{Mn} \mathrm{K} \alpha(\mathrm{MnHO})\right]$; [PET: ${ }^{4} \mathrm{Zr}$ L $\alpha$ (ZrSi), ${ }^{3} \mathrm{Y}$ L $\alpha$ (Ree3), ${ }^{5} \mathrm{Nb}$ L $\alpha(\mathrm{Nb}),{ }^{2} \mathrm{Sr}$ L $\alpha$ (stro), $\left.{ }^{4} \mathrm{Th} \mathrm{M} \alpha(\mathrm{ThSi}),{ }^{2} \mathrm{~Pb} \mathrm{M} \alpha(\mathrm{PbS})\right]$. Uma segunda etapa de análise

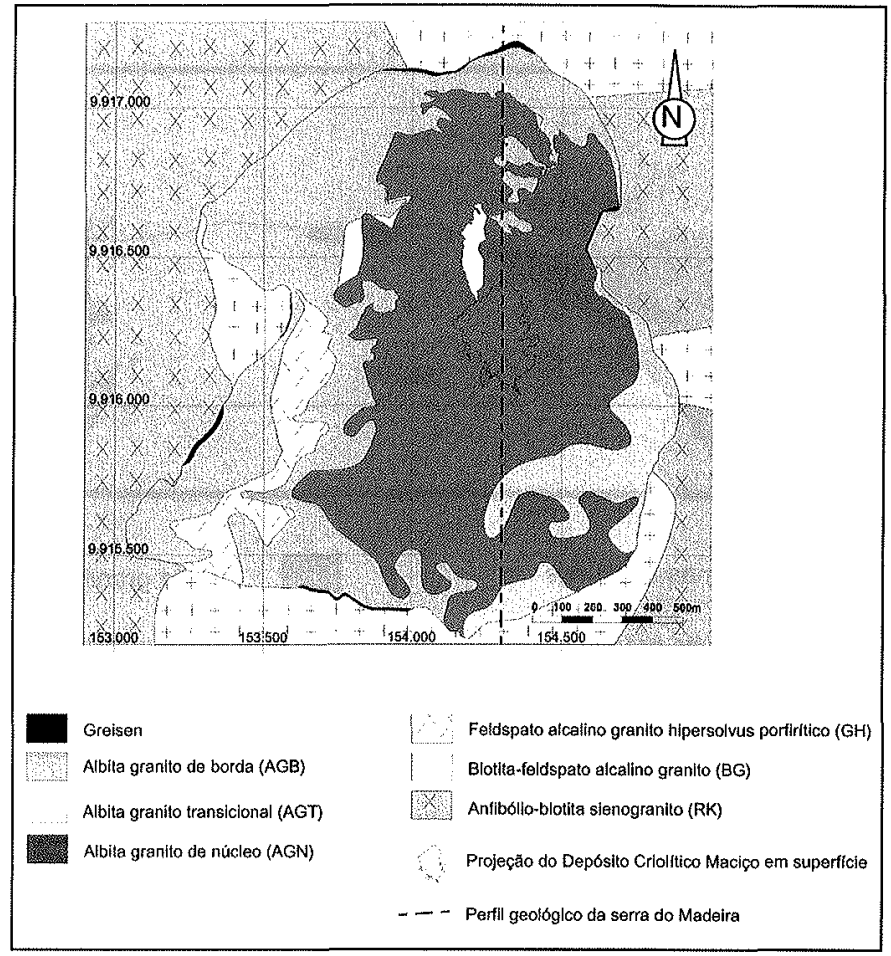

Figura 2: Mapa geológico da fácies albita granito do granito Madeira

foi desenvolvida para a quantificação de $\mathrm{Sn}, \mathrm{W}$ e $\mathrm{Sb}$, onde as condições analíticas foram: energia de $15 \mathrm{KeV}$, corrente de $10 \mathrm{nA}$, feixe de $1 \mu \mathrm{m}$, tempo de $20 \mathrm{~s}$. Nesta etapa foram utilizados para a dosagem dos elementos os seguintes cristais, radiações e padrões: [TAP:-1 FK $\alpha$ (A408), ' $\mathrm{NaK} \alpha$ (JADE), ${ }^{4} \mathrm{SiK} \alpha$ (ANOR), $\left.{ }^{5} \mathrm{TaM} \alpha(\mathrm{Ta})\right] ;$ [LIF: ${ }^{2} \mathrm{FeK} \alpha(\mathrm{MnOH}),{ }^{3} \mathrm{LaL} \alpha$ (Ree3); $\left.{ }^{4} \mathrm{TiK} \alpha(\mathrm{TiO}),{ }^{6} \mathrm{~W} \mathrm{~L} \alpha(\mathrm{W})\right]$; [PET: ${ }^{2} \mathrm{Ca} \mathrm{K} \alpha(\mathrm{ANOR}),{ }^{4} \mathrm{Sn} \mathrm{L} \alpha$ (Sn), ${ }^{3} \mathrm{Ce} \mathrm{L} \alpha$ (Ree3), ${ }^{4} \mathrm{U} \mathrm{M} \alpha$ (xGLA), ${ }^{2} \mathrm{Mn} \mathrm{K \alpha}$ (MnHO]; $\left[{ }^{4} \mathrm{Zr}\right.$ $\mathrm{L} \alpha(\mathrm{ZrSi}),{ }^{3} \mathrm{Y}$ L $\alpha$ (Ree3), ${ }^{5} \mathrm{Nb} \mathrm{L} \alpha(\mathrm{Nb}),{ }^{5} \mathrm{Sb} \mathrm{L} \alpha(\mathrm{Sb}),{ }^{4} \mathrm{Th} \mathrm{M} \alpha$ (ThSi), $\left.{ }^{2} \mathrm{~Pb} \mathrm{M} \alpha(\mathrm{PbS})\right]$. Nas análises de columbita por microssonda eletrônica, o ferro foi considerado como $\mathrm{Fe}^{+2}$. A discriminação entre $\mathrm{Fe}^{+2}$ e $\mathrm{Fe}^{+3}$ somente foi possível a partir cálculos estequiométricos (Ercit 1994).

PIROCLORO E COLUMBITA Segundo Chakoumakos (1984) e Lumpkin \& Ewing (1988 e 1992), os minerais do grupo do pirocloro possuem uma estrutura cúbica com faces centradas (ou pseudocúbica de acordo com Hodgson \& Le Bas 1992), classe hexaoctaédrica, $\mathrm{Fd} 3 \mathrm{~m} ; \mathrm{Z}=8$. A estrutura é derivada da estrutura da fluorita. A fórmula estrutural ideal do pirocloro é ${ }^{\mathrm{VIII}} \mathrm{A}_{2}{ }^{\mathrm{V}} \mathrm{B}_{2}{ }^{\mathrm{IV}} \mathrm{X}_{6}{ }^{\mathrm{V}} \mathrm{Y}$, onde $\mathrm{A}$ e $\mathrm{B}$ são cátions metálicos e $\mathrm{X}$ e $\mathrm{Y}$ são ânions. A coordenação dos íons, em caso ideal, é A X $\mathrm{Y}_{2}, \mathrm{~B} \mathrm{X}_{6}$, $\mathrm{X} \mathrm{A}_{2} \mathrm{~B}_{2}$ e Y A $\mathrm{A}_{4}$ (Lumpkin \& Ewing 1988). Removendo a combinação dos íons $\mathrm{A}$ e Y, produz-se uma estrutura defeituosa $\left({ }^{\mathrm{VI}} \mathrm{A}_{2}\right.$ ${ }^{\mathrm{VI}} \mathrm{B}_{2}{ }^{\mathrm{IV}} \mathrm{X}_{6} ;{ }^{\mathrm{VI}} \mathrm{A}{ }^{\mathrm{VI}} \mathrm{B}_{2}{ }^{\mathrm{Ill}} \mathrm{X}_{6}$ ), na qual normalmente se cristalizam os pirocloros naturais, que tem fórmula geral $A_{2-1 n} B_{2} X_{6} Y_{1-n} \cdot p$ $\mathrm{H}_{2} \mathrm{O}$ ou, segundo Hodgson \& Le Bas (1992), $\mathrm{A}_{16-\mathrm{m}} \mathrm{B}_{16} \mathrm{O}_{48}(\mathrm{O}$, $\mathrm{OH}, \mathrm{F})_{8-1 \mathrm{n}} \cdot \mathrm{pH}_{2} \mathrm{O}$ sendo que, conforme Hogarth (1989), m, n e p são números não racionais, onde cada cátion $\mathrm{B}$ coordena-se com seis íons X e cada ín X compartilha dois octaedros. Segundo Hodgson \& Le Bas (op. cit.), variações estequiométricas podem atingir extremos com $m=1,7 ; n=1,0$ e $p=2,5 \mathrm{ou}$, com a variante estrutural $\square{ }^{\mathrm{VI}} \mathrm{B}_{2}{ }^{\mathrm{III}} \mathrm{X}_{6}{ }^{\mathrm{VI}} \mathrm{M}$, conhecida como pirocloro inverso a qual, segundo Barker et al. (1976), tem a mesma estrutura $\mathrm{B}_{2} \mathrm{X}_{6}$, mas apresenta vazios na posição $A$ e substituição de ânions $Y$ por cátions monovalentes grandes. A estrutura octaédrica $B_{2} X_{6}$ 


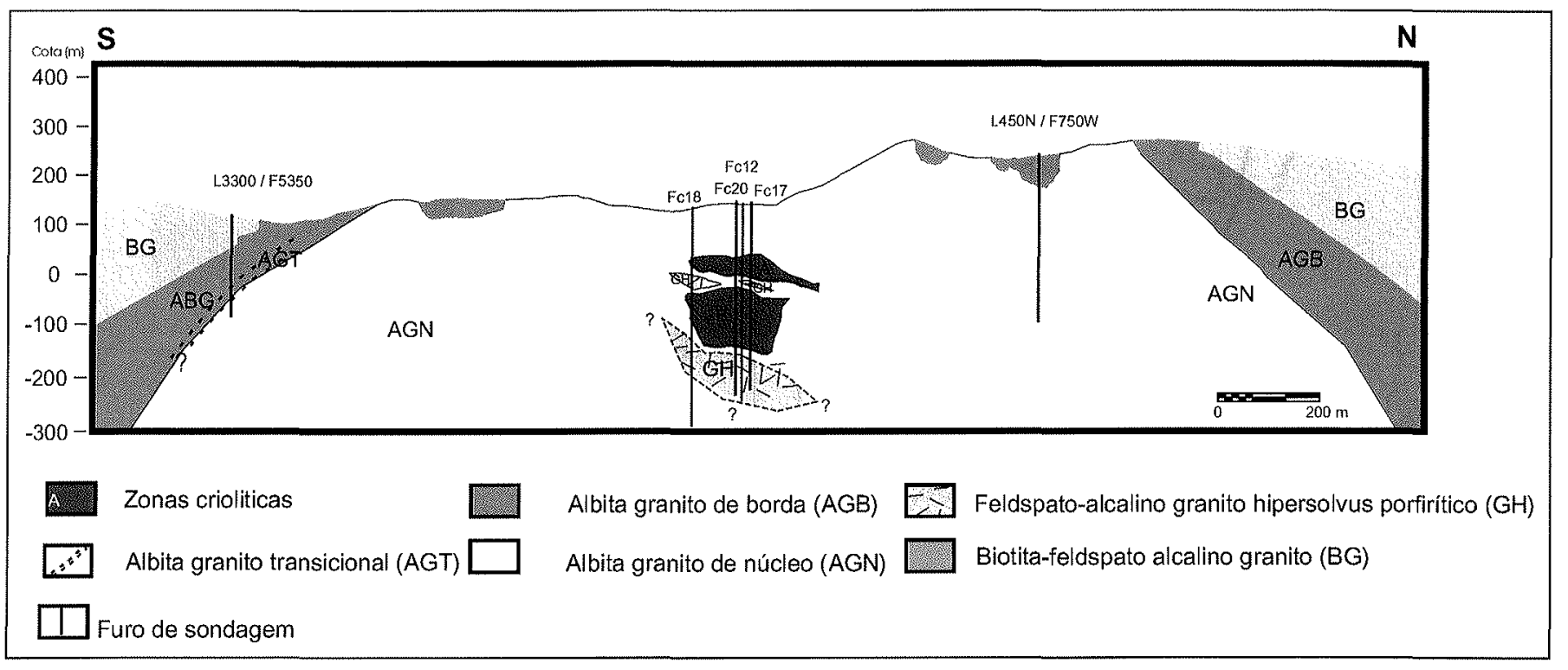

Figura 3: Perfil geológico esquemático da serra do Madeira

é considerada a feição estrutural essencial dos pirocloros. Chakoumakos \& Ewing (1985) e Chakoumakos (1984), baseados no raio iônico de Shanon (1976), afirmam que, na estrutura ideal de um pirocloro, os cátions do sítio A possuem raio iônico entre 0,087 e $0,155 \mathrm{~nm}$ e os cátions do sítio $\mathrm{B}$ têm raio iônico variando entre 0,040 a $0,078 \mathrm{~nm}$. Por essa razão, Ginsburg et al. (1958) e Hogarth (1959) (apud Van der Veen, 1963) afirmam que o tamanho da célula unitária pode assumir valores entre 10,20 e $10,39 \AA$.

Segundo Ercit (1994), a fórmula estrutural ideal da columbita é $\mathrm{AB}_{2} \mathrm{O}_{6}$, onde os sítios $\mathrm{A}$ e $\mathrm{B}$ são ocupados por cátions metálicos ligados ao oxigênio, com estrutura do tipo $\alpha \mathrm{PbO}_{2} . \mathrm{O}$ sítio A é composto principalmente por $\mathrm{Fe}^{2+}$ e $\mathrm{Mn}^{2+}(\mathrm{U}, \mathrm{Pb}, \mathrm{Ca}$, $\mathrm{Sn}, \mathrm{Na}, \mathrm{Ba}, \mathrm{Sr}, \mathrm{K}, \mathrm{Y}, \mathrm{Th}, \mathrm{Bi}, \mathrm{Cs}, \mathrm{Mg}, \mathrm{ETR})$ e o sítio B é composto por $\mathrm{Nb}$ e $\mathrm{Ta}(\mathrm{Ti}, \mathrm{Fe}, \mathrm{Sn}, \mathrm{W}, \mathrm{U}, \mathrm{V}, \mathrm{Zr}$ ), todos em coordenação VI (octaédrica). A columbita pertence ao sistema ortorrômbico (dipiramidal), grupo espacial Pbcn. As substituições $\mathrm{Fe}^{3+}$, $\mathrm{Ti}^{4+}, \mathrm{Sn}^{4+}, \mathrm{Sc}, \mathrm{Sb}^{+5}, \mathrm{~W}^{6+}$ aumentam o volume da célula unitária e a desordem ixiolítica que é definida como o grau de ordenação dos cátions durante a cristalização de fases individuais. Segundo Ohnenstetter \& Piantone (1988), os pólos são ordenados enquanto que os termos intermediários (pseudo-ixiolitas) são desordenados. A célula unitária da columbita $\left(\mathrm{Fe}^{+2} \mathrm{Nb}_{2} \mathrm{O}_{6}\right.$, tendo $78,72 \%$ de $\mathrm{Nb}_{2} \mathrm{O}_{5}$ e $21,28 \%$ de $\mathrm{FeO}$ ) tem os seguintes parâmetros cristalográficos: $a=5,746 \AA ; b=14,30 \AA$ e c $=417,23$ $\AA$ (www.webmineral.com).

CONTEXTO GEOLÓGICO A área de Pitinga localizase na porção sul do Escudo das Güianas (Almeida et al. 1981, Gibbs e Barron 1983) e faz parte da Província Amazônia Central de Tassinari et al. (1999) e da Província Tapajós-Parima de Santos (2000). A maior parte da área de Pitinga é constituída por rochas vulcânicas ácidas e piroclásticas do Grupo Iricoumé, com idade U-Pb em zircão de $1962(+42-33)$ Ma (Schobbenhaus et al. 1994) e e ${ }^{207} \mathrm{~Pb} /{ }^{206} \mathrm{~Pb}$ em zircão de $1888 \pm 3 \mathrm{Ma}$ (Costi et al. 2000 apud Costi 2000). Granitos tipo A intrudem as rochas do Grupo Iricoumé. Entre estes granitos, destacam-se os corpos intrusivos multifásicos Madeira e Água Boa que são portadores do minério primário de Sn (Horbe et al. 1991). Costi (2000) dividiu o granito Madeira nas fácies: anfibólio-biotita-sienogranito, biotita-feldspato alcalino granito, feldspato-alcalino granito hipersolvus porfirítico e albita granito. Esta última (Figura 2) subdivide-se nas subfácies AGN e AGB.

Segundo Costi (2000), a AGN é um granito subsolvus de coloração acinzentada, constituído essencialmente por quartzo, albita e feldspato potássico. Texturalmente, é porfirítico ou seriado com granulação fina a média. Os minerais varietais são criolita, mica escura tetra-ferrifera, polilitionita e riebeckita. As fases acessórias são zircão, cassiterita, minerais do grupo do pirocloro e torita. A subfácies AGB tem coloração marron escura a avermelhada. Texturalmente, é similar a AGN, diferenciando-se desta por ser oxidada e fortemente alterada. A associação mineral é composta por quartzo, albita e feldspato potássico, tendo como minerais varietais fluorita, cassiterita, zircão, hematita, torita e columbita.

$\mathrm{O}$ albita granito tem uma associação metalogenética de $\mathrm{Sn}$ $\mathrm{Nb}-\mathrm{Zr}$-ETR e F (criolita $=\mathrm{Na}_{3} \mathrm{AlF}_{6}$ ) com características tanto da associação peralcalina quanto da peraluminosa. Apenas a fácies albita granito é mineralizada; as subfácies AGN e AGB são portadoras da mineralização de $\mathrm{Sn}$, entretanto, os demais minérios repartem-se distintamente. $\mathrm{Na} A G N$, ocorrem um depósito criolítico maciço (DCM), minério disseminado de criolita e minério disseminado de $\mathrm{Nb}$ e $\mathrm{Ta}$ (unicamente pirocloro). $\mathrm{Na} \mathrm{AGB}$, considerada resultante da oxidação do $A G N$, a mineralização de $\mathrm{F}$ é representada por fluorita (subeconômica) e o minério de $\mathrm{Nb}$ e Ta é a columbita (Costi 2000).

O DCM é formado por zonas de enriquecimento denominadas zonas criolíticas A e B (Fig. 3) que ocorrem, em conjunto, desde a cota $+78,53 \mathrm{~m}$ até a cota $-163,20 \mathrm{~m}$. Internamente, as zonas são formadas por lentes e/ou bolsões pegmatóides subhorizontais, com extensão lateral de até $300 \mathrm{~m}$ e espessura de até 30 $\mathrm{m}$, com intercalações de AGN e de granito hipersolvus. O DCM é bordejado por uma auréola constituída por feldspato alcalino mesopertítico associado a quartzo leitoso e hialino e, em menores proporções, concentrações maciças de micas escuras, bem como criolita e galena, estas últimas em porções localizadas.

\section{PIROCLORO E COLUMBITA DO ALBITA GRANITO} Distribuição, observações petrográficas e ao microscópio eletrônico de varredura No presente trabalho, são identificadas 3 variedades de pirocloro que podem ocorrer individualmente ou num mesmo cristal (ver mais adiante os casos específicos): U-Pb-pirocloro, $\mathrm{Pb}$-U-pirocloro e U-pirocloro. $\mathrm{De}$ um modo geral, os 3 tipos não podem ser distinguidos opticamente, 

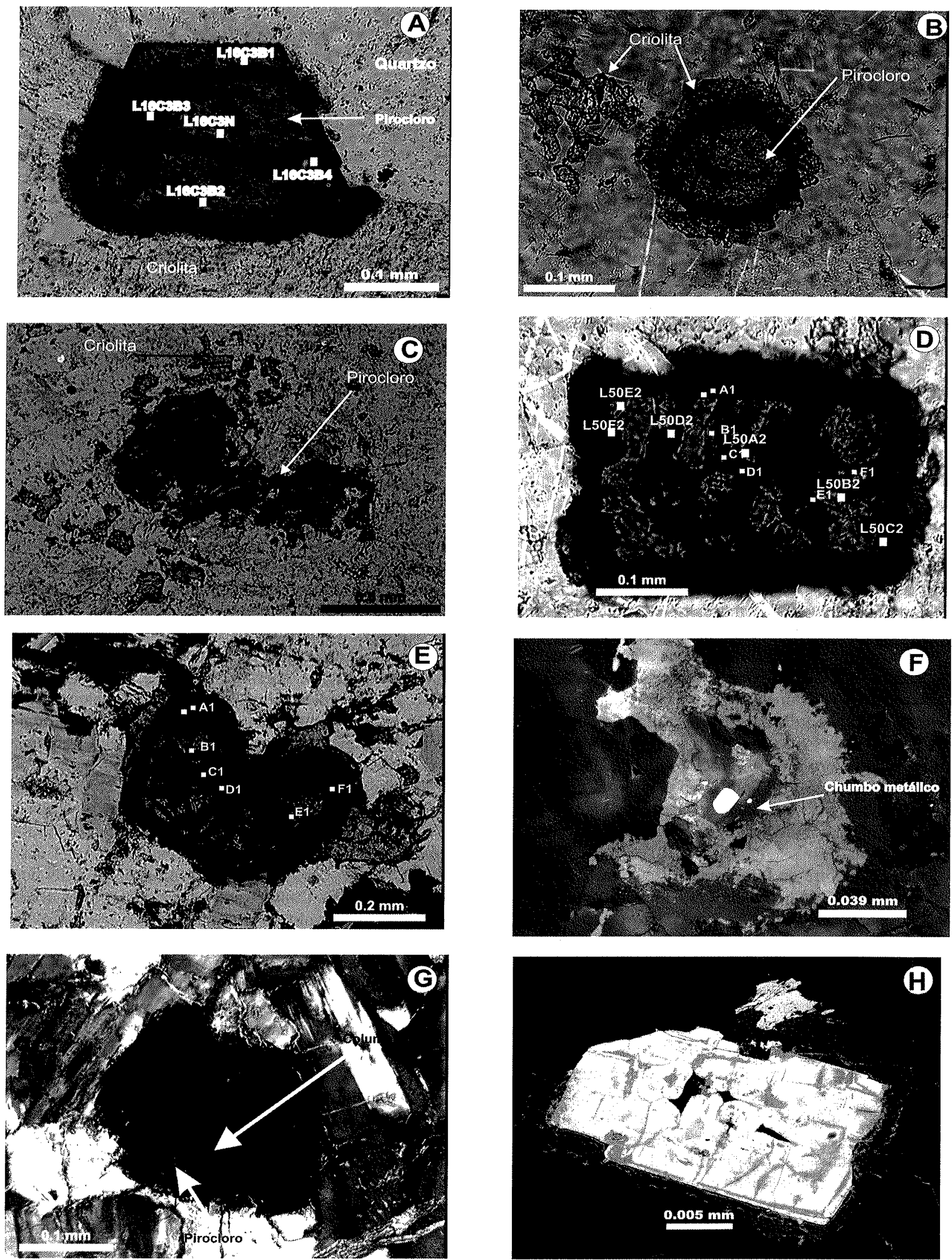

Figura 4: Fotomicrografias. A: pirocloro com alteração incipiente, observar contato retilíneo com o quartzo e contato reativo com a criolita (LN); B: pirocloro com borda ferruginosa e auréola reativa com criolita (LN); C: pirocloro com borda reativa com criolita $(L N) ; D: P b-U$-pirocloro com borda ferruginosa (LN); E: cristal de pirocloro composto por Pb-U-pirocloro (mais escuro) e U-Pb-pirocloro (mais claro) (LN); $(F)$ imagem MEV (elétrons retroespalhados) de pirocloro com exsolução de chumbo metálico; $G$ : columbita com resquícios de U-pirocloro; H: imagem $M E V$ (elétrons retroespalhados) de pirocloro afetado por columbitização seguindo planos preferenciais 
necessitando do apoio de análises ao microscópio eletrônico de varredura (MEV) e/ou microssonda eletrônica (MSE). O mesmo ocorre na identificação da columbita em pirocloro parcialmente columbitizadoe, num estágio mais avançado da columbitização, na identificação de pirocloro relicto em columbita.

$\mathrm{O}$ U-Pb-pirocloro ocorre principalmente acima da zona criolítica A. Nas zonas criolíticas A e B, este pirocloro ocorre apenas nas amostras de albita granito intercaladas nas respectivas porções basais. $\mathrm{O} \mathrm{Pb}-\mathrm{U}$-pirocloro tem uma distribuição mais ampla nas zonas criolíticas. Nas amostras de AGN mais distais (AGNEX), encontra-se apenas $\mathrm{Pb}$-U-pirocloro. O U-pirocloro é observado unicamente na subfácies transicional.

Os grãos de pirocloro (Fig. 4a) são marrons, amarelos ou caramelos, são subédricos a euédricos e têm tamanho variando entre $0,07 \mathrm{~mm}$ e $0,41 \mathrm{~mm}$. Os cristais ocorrem principalmente no interstício dos grãos de albita e dos demais minerais acessórios (cassiterita, zircão, micas e anfibólio). Também ocorrem inclusos em quartzo e, localmente, em feldspatos. Os contatos dos grãos de pirocloro com os de albita e criolita em geral apresentam bordas reativas, especialmente com este último mineral (Figuras 4b e 4c). Os contatos com zircão e quartzo são retilíneos, límpidos, indicando ausência de reação.

Cristais opticamente mais homogêneos, como o da figura $4 a$, são mais típicos do U-Pb-pirocloro. $\mathrm{O}$ U-Pb-pirocloro e o $\mathrm{Pb}-\mathrm{U}$ pirocloro podem ocorrer num mesmo cristal (Figuras $4 \mathrm{~d}$ e $4 \mathrm{e}$ ), assim como o $\mathrm{Pb}$-U pirocloro e o U-pirocloro. $\mathrm{O} \mathrm{U}$-Pb-pirocloro e o U-pirocloro não são observados numa mesma amostra. A transformação de um pirocloro para outro pode iniciar-se segundo planos preferenciais de fratura ou clivagem (Fig. 4h) ou sem controle aparente. Pirocloros com diferentes intensidades de alteração podem ocorrer numa mesma amostra; aqueles em contato com a criolita são sempre os mais alterados. Quanto mais heterogêneo opticamente for o cristal, maior a variação composicional. Nas bordas dos três tipos de pirocloro, são observadas auréolas de óxido de ferro (Fig. 4d), mais desenvolvidas no $\mathrm{Pb}$-U-pirocloro e no U-pirocloro do que no U-Pb-pirocloro. Interiormente ao $\mathrm{Pb}$-U-pirocloro e U-pirocloro, ocorrem cristais individuais ou aglomerados opacos, observáveis apenas ao $\mathrm{MEV}$, que, nos casos analisados, são constituídos unicamente por chumbo (Fig. 4f).

A columbita ocorre de forma quase generalizada nos furos que atravessam o DCM e nas amostras do albita granito transicional. Entretanto, não é observada nas amostras da AGN dos furos mais distais. Os grãos de columbita possuem formas e dimensões semelhantes às do pirocloro original, podendo conter pirocloro relicto em quantidades variáveis (Fig. 4g). Os contatos com o quartzo, albita e zircão são retilíneos, localmente irregulares, e em geral límpidos. O contato com a criolita é retilíneo a embaiado, e com a mica branca é irregular. Os grãos constituídos exclusivamente (ou quase exclusivamente) por columbita tendem a ser isótropos e geralmente subédricos. Nestes, observa-se ao MEV uma distribuição de elementos bastante uniforme, com exceção do $\mathrm{Fe}$ mais abundante nas bordas, o que se deve, provavelmente à auréola rica em Fe formada nos estágios mais precoces de alteração (ainda como pirocloro).

Composição química do pirocloro Composições químicas e fórmulas estruturais representativas das 3 variedades de pirocloro, calculadas com base em Ercit et al. (1994), são apresentadas na Tabela 1. No diagrama de classificação para o grupo do pirocloro (Hogarth, 1977), baseado nos cátions do sítio $B$, as 3 variedades encontradas enquadram-se no subgrupo pirocloro (Fig. 5). Segundo o esquema de classificação do referido autor, os cátions do sítio A definem as variedades individuais em cada subgrupo. Assim, no caso de Pitinga, o pirocloro foi classificado em 3 variedades: $\mathrm{U}$-Pb-pirocloro, $\mathrm{Pb}$-U-pirocloro e U-piroclo-

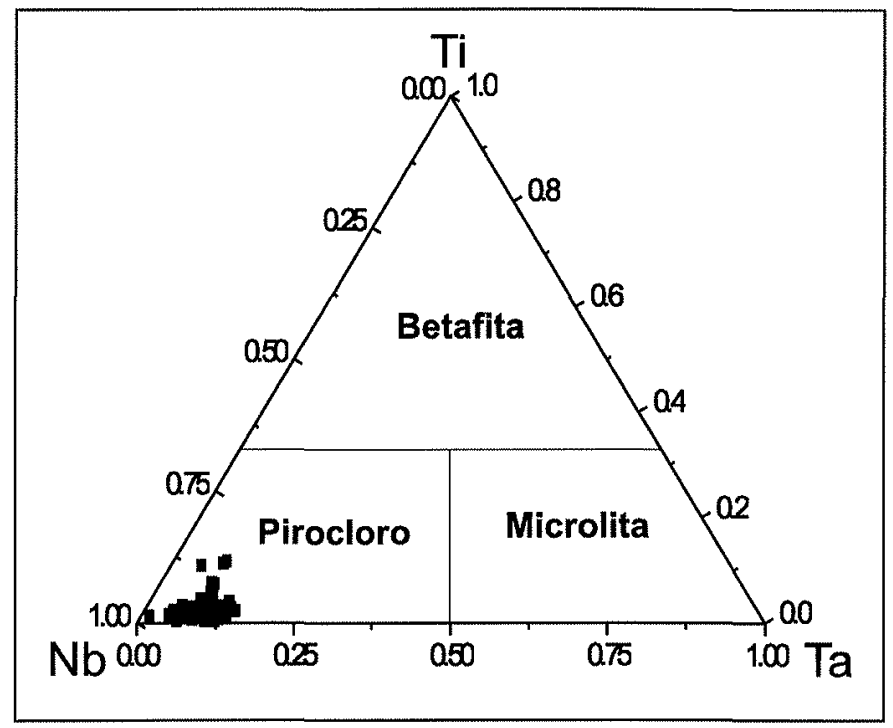

Figura 5: Diagrama de classificação $\mathrm{Ti} \times \mathrm{Nb} \times \mathrm{Ta}$ (Ercit et al., 1994) para os pirocloros da mina Pitinga.

ro (Fig. 6). Esta figura ilustra as características mais marcantes encontradas, como o empobrecimento muito acentuado em $\mathrm{Pb}$ é acompanhado pelo enriquecimento relativo em $\mathrm{U}$ e $\mathrm{Nb}$, e a existência de toda a gama de composições ao longo destas substituições no conjunto de amostras estudadas. Por outro lado, em uma determinada amostra, na passagem do U-Pb-pirocloro para a columbita nem sempre há formação de fases intermediárias ( $\mathrm{Pb}$-U-pirocloro ou U-pirocloro), ou seja, provavelmente a formação das diferentes variedades depende da intensidade de alteração, que pode variar em diferentes porções de um grão em função de diferenças cristalográficas (clivagens, fraturas, defeitos cristalinos) ou da composição química.

$\mathrm{Na}$ tabela 2 constam as variações nas concentrações dos óxidos dos principais cátions dos sítios A e B. Nesta tabela, o $\mathrm{Pb}-\mathrm{U}$-pirocloro é apresentado separadamente, conforme a amostragem: Pb-U-pirocloro $\mathrm{N}$ (amostras do AGN das zonas criolíticas) e $\mathrm{Pb}$-U-pirocloroNEX (amostras do AGN dos furos distais - AGNEX). Considerando os valores médios dos óxidos, observa-se uma evolução contínua desde o U-Pb-pirocloro até o U-pirocloro, marcada pela perda de $\mathrm{Pb}$ e enriquecimento relativo em $\mathrm{U}, \mathrm{Nb}$, Ta e Ti. Destaca-se o grande enriquecimento em $\mathrm{Nb}_{2} \mathrm{O}_{5}$ do $\mathrm{U}-\mathrm{Pb}$-pirocloro $(38,42 \%)$ para o $\mathrm{Pb}$-U-pirocloro $(50,29 \%)$. Com relação a outros constituintes (Tab. 3), ocorrem algumas diferenças quase sistemáticas entre as 3 variedades, mais especialmente entre o U-Pb-pirocloro e o $\mathrm{Pb}$-U-pirocloro. Este último é mais rico em $\mathrm{Ca}, \mathrm{Ce}, \mathrm{Sn}$ e $\mathrm{F}$.

Nos diagramas binários de correlação (Figuras $7 \mathrm{a}, \mathrm{b}, \mathrm{c}, \mathrm{d}$ ), destaca-se bem o caráter contínuo das substituições entre os elementos principais $(\mathrm{Pb}, \mathrm{U}, \mathrm{Nb}, \mathrm{Ta}$ e Ti) na passagem do $\mathrm{U}-$ $\mathrm{Pb}$-pirocloro até o U-pirocloro. $\mathrm{O} \mathrm{Pb}$ pode ser usado, portanto, como um marcador do grau de transformação do pirocloro. Nos diagramas de correlação do $\mathrm{Pb}$ com $\mathrm{Ca}, \mathrm{Ce}, \mathrm{Sn}$ e $\mathrm{F}$ (Figuras $7 \mathrm{e}, \mathrm{f}, \mathrm{g}, \mathrm{h}$ ), constata-se que estes elementos são enriquecidos nos pirocloros, concomitantemente à perda de $\mathrm{Pb}$, desde o U$\mathrm{Pb}$-pirocloro (U-Pb-Py) (AGN) até o Pb-U-pirocloro (Pb-U-Py) (AGNEX). Entretanto, na passagem para o U-pirocloro (U-Py) (AGT), essa sequiência é descontinuada, ocorrendo o empobrecimento nestes 4 elementos. O Fe no pirocloro (Fig. 7i) tem comportamento contrário ao dos elementos anteriores, mostrando empobrecimento ao longo da passagem do U-Pb-pirocloro (AGN) até o Pb-U-Py (AGNEX) e enriquecimento na passagem para o U-Py (AGT). Possivelmente, a auréola rica em Fe exis- 


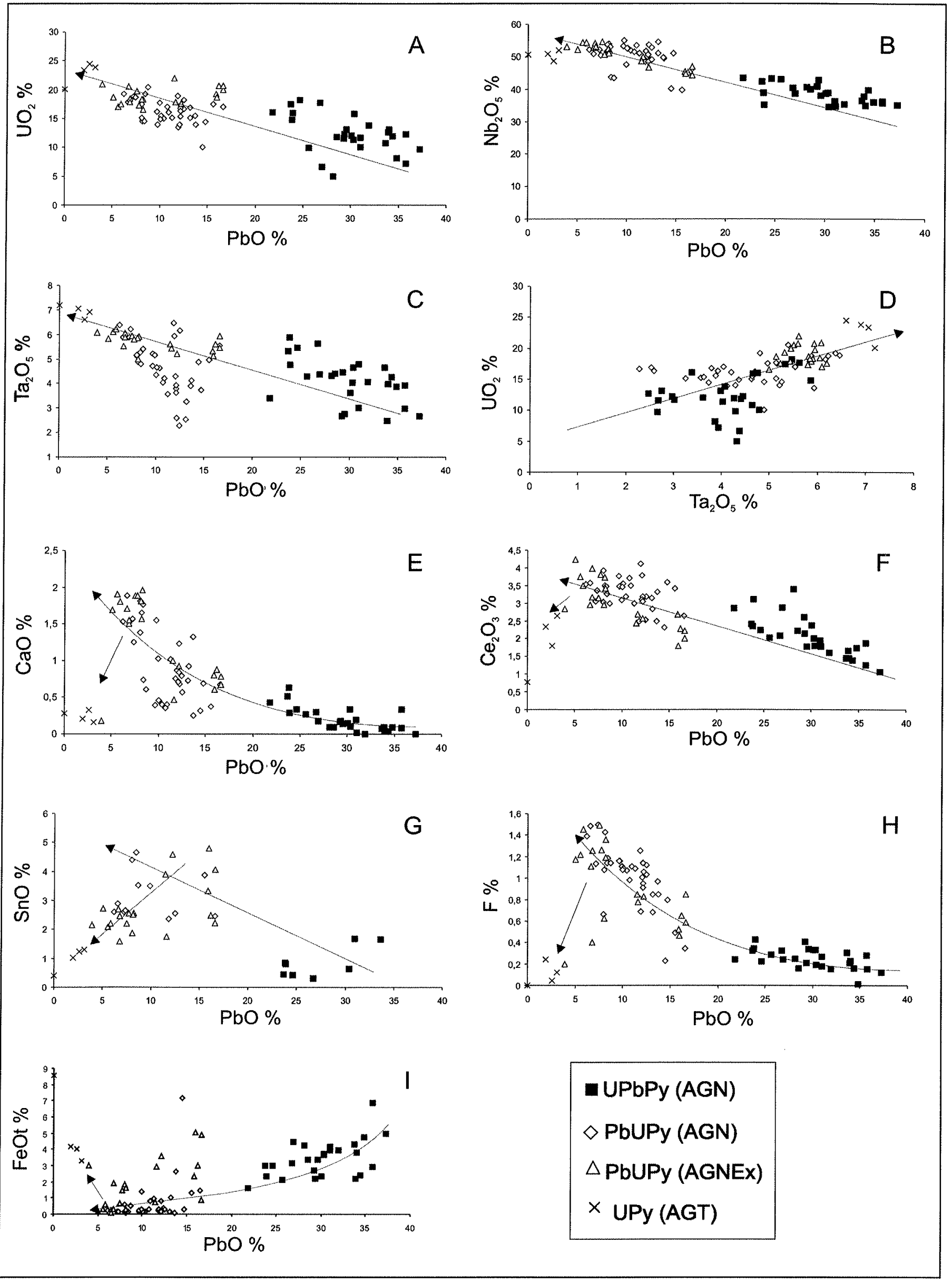

Figura 6: Diagrama triangular Pb $\times$ U $x \mathrm{Nb}$ de classificação (Hogarth 1977), para as variedades de pirocloro do albita granito Madeira. 
Tabela 1: Análises por microssonda eletrônica (WDS) em peso\% e fórmulas estruturais das variedades de pirocloro das subfácies $A G N, A G N E x$ e $A G T$.

\begin{tabular}{|c|c|c|c|c|c|c|}
\hline Pirocloro & UPbPy & UPbPy & PbUPy & PbUPy & UPy & UPy \\
\hline Prof. (m) & 95,18 & 115,45 & 231,96 & 95,18 & 150,19 & 150,19 \\
\hline Subfácies & $\mathrm{AGN}$ & $\mathrm{AGN}$ & AGNEx & $\mathrm{AGN}$ & AGT & AGT \\
\hline Ponto & PONTO 1 & L7D-B1 & L50B4 & L5D-A2 & L5B6 & L5C6 \\
\hline $\mathrm{Nb}_{2} \mathrm{O}_{5}$ & 36,44 & 42,36 & 54,26 & 49,04 & 51,89 & 50,91 \\
\hline $\mathrm{Ta}_{2} \mathrm{O}_{5}$ & 4,64 & 5,33 & 6,20 & 6,16 & 6,90 & 7,06 \\
\hline $\mathrm{SiO}_{2}$ & nd & nd & nd & nd & nd & nd \\
\hline $\mathrm{TiO}_{2}$ & 0,43 & 0,84 & 1,46 & 1,07 & 1,34 & 0,90 \\
\hline $\mathrm{ZrO}_{2}$ & 0,13 & 0,09 & 0,06 & nd & 0,17 & 0,02 \\
\hline $\mathrm{ThO}_{2}$ & 0,71 & 0,31 & 0,20 & 0,49 & 0,49 & 0,47 \\
\hline $\mathrm{UO}_{2}$ & 10,80 & 17,47 & 17,49 & 18,22 & 23,86 & 23,39 \\
\hline $\mathrm{Y}_{2} \mathrm{O}_{3}$ & nd & 0,16 & 0,20 & 0,30 & 0,23 & nd \\
\hline $\mathrm{La}_{2} \mathrm{O}_{3}$ & 0,20 & 0,29 & 0,91 & 0,53 & 0,69 & 0,43 \\
\hline $\mathrm{Ce}_{2} \mathrm{O}_{3}$ & 1,44 & 2,40 & 3,49 & 2,53 & 2,64 & 2,32 \\
\hline $\mathrm{CaO}$ & 0,07 & 0,51 & 1,79 & 0,78 & 0,15 & 0,20 \\
\hline $\mathrm{MnO}$ & 0,09 & 0,10 & 0,16 & 0,07 & 0,96 & 0,88 \\
\hline $\mathrm{FeO}$ & 4,30 & 2,98 & 0,58 & 0,35 & 3,32 & 4,13 \\
\hline $\mathrm{PbO}$ & 33,67 & 23,68 & 5,84 & 12,48 & 3,12 & 1,95 \\
\hline $\mathrm{Na}_{2} \mathrm{O}$ & 0,73 & 1,02 & 1,23 & 0,83 & 0,26 & 0,13 \\
\hline $\mathrm{SnO}_{2}$ & 1,64 & 0,45 & 2,19 & 2,55 & 1,30 & 1,02 \\
\hline $\mathrm{WO}_{3}$ & 0,01 & 0,13 & 0,05 & 0,42 & 0,05 & 0,38 \\
\hline $\mathrm{Sb}_{2} \mathrm{O}_{5}$ & nd & nd & nd & nd & nd & nd \\
\hline $\mathrm{F}$ & 0,30 & 0,32 & 1,45 & 1,12 & 0,12 & 0,24 \\
\hline TO'TAL & 95,67 & 98,54 & 97,64 & 97,00 & 97,56 & 94,49 \\
\hline \multicolumn{7}{|c|}{ Fórmula estrutural com base em Ohnenstetter \& Piantone (1988) } \\
\hline $\mathrm{Pb}^{+2}$ & 6,674 & 4,279 & 0,906 & 2,141 & 0,463 & 0,290 \\
\hline $\mathrm{U}^{+4}$ & 1,771 & 2,607 & 2,240 & 2,590 & 2,906 & 2,851 \\
\hline $\mathrm{Th}^{+4}$ & 0,120 & 0,049 & 0,267 & 0,074 & 0,060 & 0,059 \\
\hline $\mathrm{Mn}^{+2}$ & 0,060 & 0,057 & 0,081 & 0,041 & 0,443 & 0,408 \\
\hline $\mathrm{Na}^{+1}$ & 1,044 & 1,336 & 1,374 & 1,038 & 0,289 & 0,145 \\
\hline $\mathrm{Ca}^{+2}$ & 0,060 & 0,369 & 1,108 & 0,539 & 0,094 & 0,119 \\
\hline $\mathrm{Y}^{+3}$ & nd & 0,057 & 0,065 & 0,106 & 0,067 & nd \\
\hline $\mathrm{La}^{+3}$ & 0,060 & 0,074 & 0,194 & 0,123 & 0,141 & 0,086 \\
\hline $\mathrm{Ce}^{+3}$ & 0,394 & 0,590 & 0,736 & 0,588 & 0,530 & 0,467 \\
\hline $\mathrm{Sn}^{+4}$ & 0,479 & 0,123 & 0,501 & 0,654 & 0,282 & 0,224 \\
\hline $\mathrm{Sb}^{+5}$ & nd & nd & nd & nd & nd & nd \\
\hline Soma A & 10,661 & 9,541 & 7,470 & 7,894 & 5,275 & 4,649 \\
\hline $\mathrm{Nb}^{+5}$ & 12,133 & 12,861 & 14,092 & 14,153 & 12,839 & 12,616 \\
\hline $\mathrm{Ta}^{+5}$ & 0,933 & 0,975 & 0,970 & 1,070 & 1,027 & 1,053 \\
\hline $\mathrm{Ti}^{+4}$ & 0,240 & 0,426 & 0,631 & 0,515 & 0,557 & 0,375 \\
\hline $\mathrm{Zr}^{+4}$ & 0,043 & 0,033 & 0,016 & nd & 0,047 & 0,007 \\
\hline $\mathrm{Si}^{+4}$ & nd & nd & nd & nd & nd & nd \\
\hline $\mathrm{Fe}^{+2}$ & 2,652 & 1,680 & 0,283 & 0,188 & 1,523 & 1,896 \\
\hline $\mathrm{W}^{+6}$ & nd & 0,025 & 0,008 & 0,074 & 0,007 & 0,053 \\
\hline Soma B & 16,000 & 16,000 & 16,000 & 16,000 & 16,000 & 16,000 \\
\hline $\mathrm{F}$ & 0,310 & 0,320 & 3,260 & 1,120 & 0,310 & 0,640 \\
\hline
\end{tabular}

(AGN) albita granito de núcleo; (AGNEx) albita granito de núcleo distante do depósito criolítico maciço; (AGT) albita granito transicional; (nd) não detectado.

tente nos grãos de pirocloro alterados é ligada às transformações em que ocorre a perda deste elemento no pirocloro.

A análise estatística também possibilitou verificar a existência de substituições complexas, envolvendo cátions de sítios diferentes. A substitutição envolvendo o $\mathrm{Sn}$ foi, provavelmente, do tipo $3 \mathrm{~Pb}^{2+}(\mathrm{A})+\mathrm{M}^{3+}(\mathrm{B})=\mathrm{M}^{5+}(\mathrm{B})+\mathrm{Sn}^{4+}(\mathrm{A})$ que apresenta uma excelente correlação negativa (Fig. 8). Nenhuma correlação significativa é obtida quando o Sn é testado com número de oxidação +2. Por outro lado, ao longo do processo de alteração do pirocloro, existem outras substituições que implicam o aumento gradual no número de vacâncias no sítio cristalográfico $\mathrm{A}$. 
Tabela 2: Concentração (peso \%) dos principais óxidos constituintes das 3 variedades de pirocloro

\begin{tabular}{|c|c|c|c|c|c|}
\hline & $\mathrm{PbO} \%$ & $\mathrm{UO}_{2} \%$ & $\mathrm{Nb}_{2} \mathrm{O}_{5} \%$ & $\mathrm{Ta}_{2} \mathrm{O}_{5} \%$ & $\mathrm{TiO}_{2} \%$ \\
\hline U-Pb PyN & $21,80-37,23$ & $4,96-18,17$ & $34,52-43,51$ & $2,47-5,86$ & $0,24-1,90$ \\
\hline Média & $(29,855)$ & $(12,26)$ & $(38,42)$ & $(4,10)$ & $(0,86)$ \\
\hline Pb-U PyN & $6,17-16,58$ & $10,06-20,49$ & $39,81-54,95$ & $2,28-6,45$ & $0,37-1,68$ \\
\hline Média & $(10,94)$ & $(16,22)$ & $(50,29)$ & $(4,65)$ & $(1,14)$ \\
\hline Pb-UPyNEx & $3,90-16,62$ & $16,58-21,94$ & $44,22-54,64$ & $5,00-6,09$ & $0,35-1,75$ \\
\hline Média & $(9,84)$ & $(18,88)$ & $(50,28)$ & $(5,69)$ & $(1,15)$ \\
\hline U-PyT & $0-3,12$ & $20,09-24,48$ & $48,71-50,91$ & $6,60-7,19$ & $0,90-1,89$ \\
\hline Média & $(1,91)$ & $(22,95)$ & $(50,53)$ & $(6,94)$ & $(1,39)$ \\
\hline
\end{tabular}

Tabela 3: Concentração (peso \%) de $\mathrm{CaO}, \mathrm{Ce}_{2} \mathrm{O}_{3}, \mathrm{SnO}$ e $\mathrm{F}$ das diferentes variedades de pirocloro e média das concentrações dos pontos analisados.

\begin{tabular}{|c|c|c|c|c|}
\hline & $\mathrm{CaO} \%$ & $\mathrm{Ce}_{2} \mathrm{O}_{3} \%$ & $\mathrm{SnO} \%$ & $\mathrm{~F} \%$ \\
\hline UPbPyN & $<0,01-0,63$ & $1,07-3,39$ & $0,31-1,67$ & $0,01-0,42$ \\
\hline Média & $(0,19)$ & $(2,05)$ & $(0,85)$ & $(0,25)$ \\
\hline PbUPyN & $0,17-1,95$ & $1,78-4,23$ & $1,57-4,78$ & $0,19-1,49$ \\
\hline Média & $(1,04)$ & $(3,16)$ & $(2,89)$ & $(0,97)$ \\
\hline UPyT & $0,16-0,32$ & $0,77-2,65$ & $0,39-1,31$ & $<0,01-0,24$ \\
\hline Média & $(0,24)$ & $(1,89)$ & $(0,99)$ & $(0,10)$ \\
\hline
\end{tabular}

Composição química da columbita Composições químicas representativas da columbita estudada, com as respectivas fórmulas estruturais calculadas com base em 24 oxigênios, são apresentadas na Tabela 4. O diagrama de classificação baseado nas razões $\mathrm{Nb} /(\mathrm{Nb}+\mathrm{Ta})$ e $\mathrm{Mn} /(\mathrm{Fe}+\mathrm{Mn}$ ) (Fig. 9) mostra tratarse de ferrocolumbita e, mais raramente, de manganocolumbita, sendo esta última encontrada apenas na zona criolítica $A$.

Destaca-se a existência de uma zonação vertical com aumento constante nos teores de $\mathrm{Nb}_{2} \mathrm{O}_{5}$ e $\mathrm{Ta}_{2} \mathrm{O}_{5}$ na columbita desde as amostras da AGN acima da zona criolítica $A$ até a zona criolítica B. As amostras da fácies de transição têm concentrações nestes elementos compatíveis com as amostras coletadas acima da zona criolítica $A$. As variações nas concentrações de $\mathrm{FeO}, \mathrm{Fe}_{2} \mathrm{O}_{3}$ e $\mathrm{MnO}$ são mais irregulares. Na Figura $10 \mathrm{a}$, observa-se a existência de uma boa correlação negativa $\mathrm{FeO}$ (total) vs $\mathrm{MnO}$ e que as 4 amostras de manganocolumbitas encontradas na zona criolítica $\mathrm{A}$, embora estejam distantes das demais em termos de composição, enquadram-se perfeitamente na referida correlação. A columbita do AGN acima da zona A e a da fácies de transição têm composições intermediárias às das duas zonas criolíticas. No diagrama $\mathrm{MnO}$ vs FeO (Fig. 10b), a boa correlação negativa persiste apenas para as amostras da zona criolítica B. A correlação desaparece totalmente no diagrama $\mathrm{MnO} v s$ $\mathrm{Fe}_{2} \mathrm{O}_{3}$ (Fig. 10c), onde observa-se que a columbita da zona criolítica A tem grande variabilidade das concentrações de $\mathrm{Fe}_{2} \mathrm{O}_{3}$ e que a columbita da zona de transição é, caracteristicamente, a mais oxidada. $\mathrm{O}$ diagrama $\mathrm{FeO}$ vs $\mathrm{Fe}_{2} \mathrm{O}_{3}$ (Fig. 10d) evidencia perfeitamente que o Fe presente na columbita da zona criolítica $B$ encontra-se essencialmente no estado reduzido.

$\mathrm{O} \mathrm{Pb}$ é detectado em cerca de $35 \%$ das análises de columbita, sendo usualmente detectado nas amostras oriundas da zona criolítica $\mathrm{A}$, na qual seu teor atinge até $1,03 \%$ de $\mathrm{PbO}$. Sua presença é gradualmente mais rara em profundidade, tendo sido detectado em apenas 2 amostras da zona criolítica B. Na columbita da subfácies transicional, $\mathrm{O} \mathrm{Pb}$ é detectado em apenas uma análise, com teor de $1,10 \%$ de $\mathrm{PbO}$, o mais alto encontrado no conjunto estudado; necessitam-se análises adicionais para verificar o significado deste resultado. $O$ urânio é detectado na grande maioria das amostras de columbita e com concentrações de até $2,43 \%$ de $\mathrm{UO}_{2}$. Os teores deste óxido também diminuem com o aumento da profundidade, sendo que, na columbita da zona criolítica $B$, a concentração média é de apenas $0,25 \%$. Os teores de $\mathrm{SnO}_{2}$ na columbita variam de $0,67 \%$ até $3,48 \%$ sem que haja um padrão de distribuição definido.

$\mathrm{O}$ tratamento estatístico dos resultados analíticos possibilita identificar algumas substituições complexas. Por exemplo, os sítios $\mathrm{A}$ e $\mathrm{B}$, quando analisados independentemente, apresentam as correlações $-0,93$ para os cátions $\mathrm{M}^{+2} \times \mathrm{M}^{+3}$ (sítio $\mathrm{A}$ ) $\mathrm{e}-0,82$ para os cátions $\mathrm{M}^{+4} \times \mathrm{M}^{+5}$ (sítio $\mathrm{B}$ ). Estes resultados corroboram a atuação da substituição euxenítica (Ercit 1994): $\mathrm{M}^{2+}(\mathrm{A})+\mathrm{M}^{5+}$ (B) $\Leftrightarrow \mathrm{M}^{3+}(\mathrm{A})+\mathrm{M}^{4+}(\mathrm{B})$. Verifica-se, também, o enriquecimento em cátions $\mathrm{M}^{+5}\left(\mathrm{Ta}^{+5}, \mathrm{Nb}^{+5}\right)$ em relação aos cátions $\mathrm{M}^{+4}$ $\left(\mathrm{Si}^{+4}, \mathrm{Ti}^{+4}, \mathrm{Sn}^{+4}, \mathrm{U}^{+4}, \mathrm{Th}^{+4}, \mathrm{Zr}^{+4}\right)$ na columbita situada na zona criolítica B. A columbita da subfácies de transição é, entretanto, relativamente rica em cátions $\mathrm{M}^{+4}$ em relação aos $\mathrm{M}^{+5}$. Por outro lado, nesta última columbita, ocorrem algumas das melhores correlações obtidas, tais como: $\mathrm{TiO}_{2} \times \mathrm{Nb}_{2} \mathrm{O}_{5}(-0,8 \mathrm{a}-0,9)$, $\mathrm{TiO}_{2}$ $x \mathrm{MnO}(-0,9 \mathrm{a}-1,0)$ e $\mathrm{MnO} \times \mathrm{Ta}_{2} \mathrm{O}_{5}(-0,9 \mathrm{a}-1,0), \mathrm{FeO}_{\mathrm{t}} \times \mathrm{Nb}_{2} \mathrm{O}_{5}$ $(-0,8$ a $-0,9)$. As quais se enquadram na substituição euxenítica.

Na maioria das análises de columbita, a quantidade de cá- 
A columbitização do pirocloro do albita granito na mina Pitinga $(A M)$ : relações com a mineralização de criolita
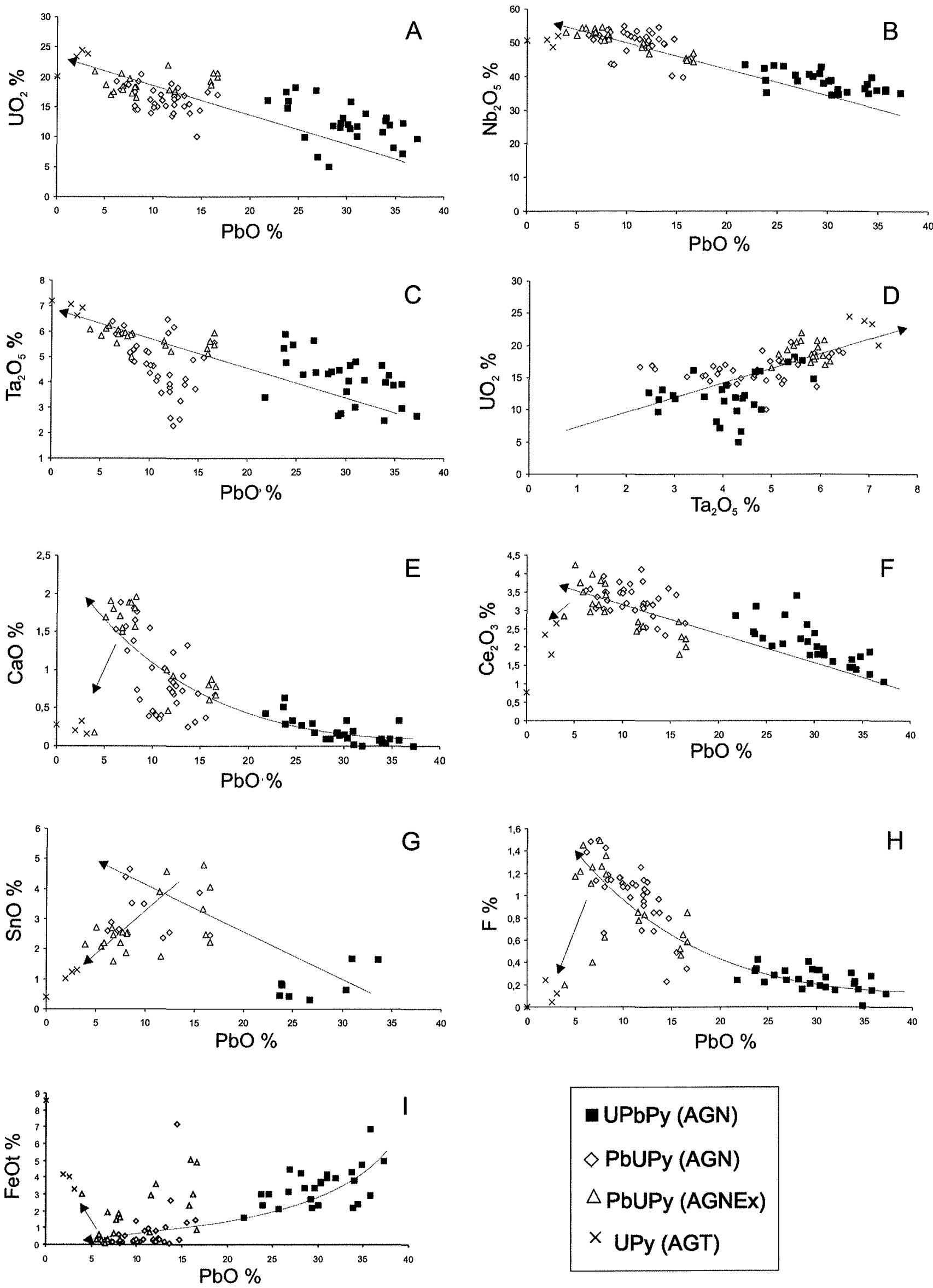

Figura 7: Diagramas binários para o pirocloro da mina Pitinga. $\mathrm{A}:\left(\mathrm{UO}_{2}\right.$ vs $\left.\mathrm{PbO}\right) ; \mathrm{B:}\left(\mathrm{Nb}_{2} \mathrm{O}_{5}\right.$ vs $\left.\mathrm{PbO}\right) ; \mathrm{C:}_{2}\left(\mathrm{Ta}_{2} \mathrm{O}_{5}\right.$ vs $\left.\mathrm{PbO}\right) ; \mathrm{D}:\left(\mathrm{UO} \mathrm{O}_{2}\right.$ vs $\left.\mathrm{Ta}_{2} \mathrm{O}_{5}\right)$; $\mathrm{E}$ : (CaO vs $\left.\mathrm{PbO}\right) ; \mathrm{F}$ : $\left(\mathrm{Ce}_{2} \mathrm{O}_{3}\right.$ vs $\left.\mathrm{PbO}\right)$; G: (SnO vs PbO); $\mathrm{H}$ : (F vs PbO); I: (FeOt vs PbO).

132

Revista Brasileira de Geociências, volume 36 (1- suplemento), 2006 


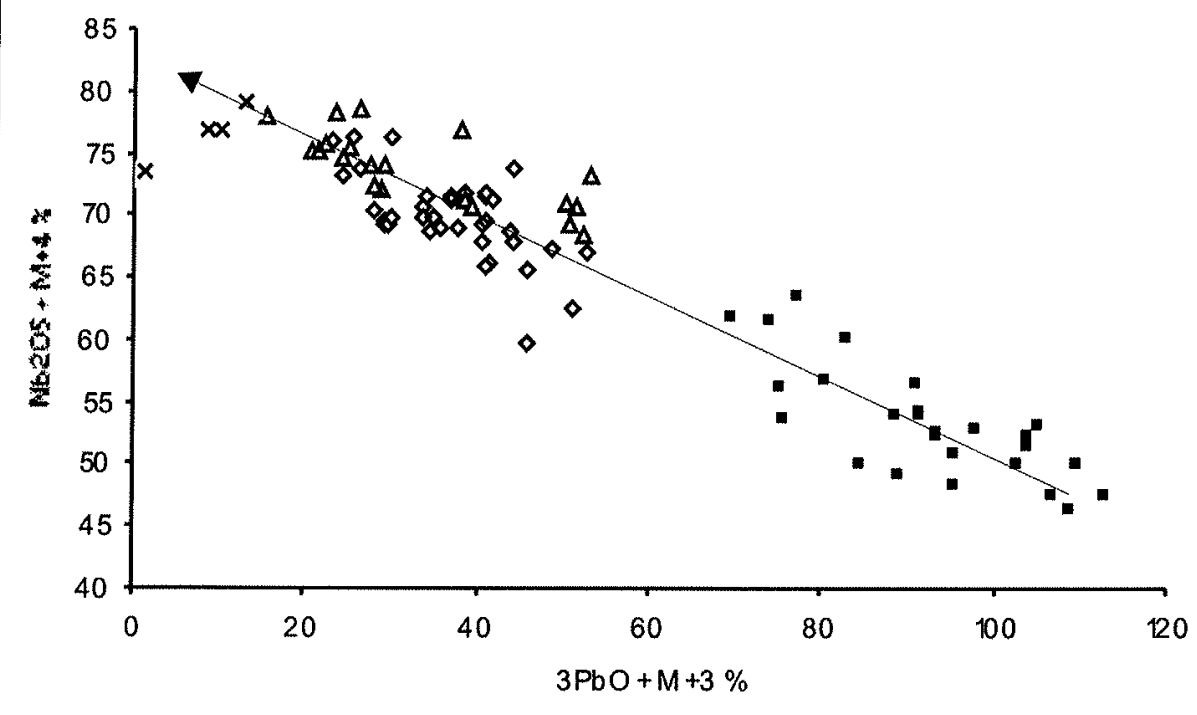

$\diamond$ PbUPy (AGN)

$\triangle$ PbUPy (AGNEx)

$\times \operatorname{UPy}(\mathrm{AGT})$

Figura 8: Diagrama $\mathrm{Nb}_{2} \mathrm{O}_{5}+M^{+4} \times 3 \mathrm{PbO}+M^{+3}$ para as diferentes variedades de pirocloro.

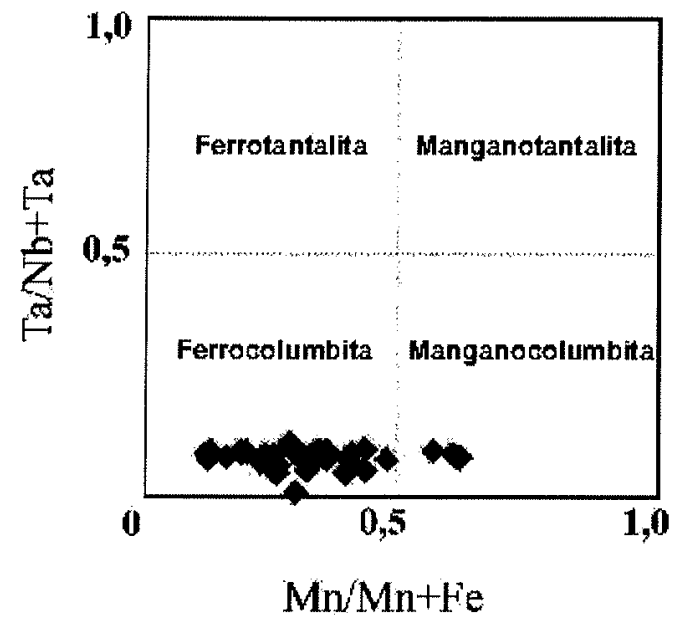

Figura 9: Diagrama de classificação $(\mathrm{Mn} /(\mathrm{Mn}+\mathrm{Fe})) \times$ (Tal $(T a+N b))$ (Moreau \& Tramasure 1964) para a columbita do albita granito Madeira.

tions no sítio $\mathrm{A}$ é superior a 4 átomos por fórmula unitária, o que indica, em princípio, que parte dos átomos atribuídos a este sítio podem pertencer ao sítio cristalográfico $\mathrm{B}$. Além disso, a boa correlação do $\mathrm{MnO}$ com o $\mathrm{FeO}_{(}(-0,8$ a $-0,9)$ e a baixa correlação do $\mathrm{MnO}$ com o $\mathrm{Fe}_{2} \mathrm{O}_{3}$ indica que, provavelmente, parte do $\mathrm{Fe}^{3+}$ pertence ao sítio cristalográfico $\mathrm{B}$. Também verifica-se, em algumas amostras, que o conteúdo de cátions do sítio cristalográfico B é superior a 8 , indicando prováveis distorções na estrutura cristalina.

DISCUSSÃO DOS RESULTADOS O U-Pb-pirocloro é uma variedade muito rara deste mineral, tendo sido descrito apenas em seis localidades do mundo (www.webmineral.com), a saber: complexo alcalino de Lovozer, depósito de Schugorsk e Monte Ploskaya (Rússia); Tai-Keu, Sibéria-Rússia; Doma de St. Peters e Mont North Sugarloaf (USA). As variedades de pirocloro do granito Madeira destacam-se, também, pelas concentrações relativamente altas de U. O U-pirocloro é descrito em pouco mais de 15 localidades, entre outras: Kasenda (Uganda), pegmatito de Boqueirãozinho (Brasil-RN), Jacupiranga (Brasil-SP), Hybla, MacDonald-Woodcox mines e Saint Lawrence Columbium mine (Canadá). $\mathrm{O}$ teor de $\mathrm{Nb}_{2} \mathrm{O}_{5}$ do pirocloro de Pitinga, em torno de $45 \%$, é o comumente encontrado neste mineral. Já o teor de $\mathrm{Sn}$ é bastante superior aos valores encontrados na literatura, o que parece estar em consonância com o caráter primário do U-Pb-pirocloro e a presença de importante mineralização estanifera magmática.

Os teores de $\mathrm{Nb}_{2} \mathrm{O}_{5}, \mathrm{Ta}_{2} \mathrm{O}_{5}$ e FeOt da columbita de Pitinga são os comumente encontrados na literatura sobre este mineral. Entretanto, deve ser destacado que a formação de columbita a partir do pirocloro representa enriquecimento de $\mathrm{Nb}_{2} \mathrm{O}_{5} \mathrm{e} \mathrm{Ta}_{2} \mathrm{O}_{5}$ da ordem de $42 \%$ e $23 \%$, respectivamente, em relação ao pirocloro original. Quanto a outros elementos, os dados publicados sobre columbitas de outras localidades são poucos (exemplos de referência), mas constata-se que a columbita de Pitinga sobressai-se pela altas concentrações de $\mathrm{Fe}_{2} \mathrm{O}_{3}$ e $\mathrm{SnO}_{2}$ (de $0,67 \%$ até $3,48 \%$ ) e, num segundo plano, pelas concentrações de $U_{2}$. Nos casos destes dois últimos óxidos, trata-se, certamente, de herança do pirocloro. A questão do $\mathrm{Fe}^{3+}$ é discutida mais adiante.

A substituição de pirocloro por columbita-tantalita, em um processo denominado columbitização por Van der Veen (1963), foi originalmente descrita nos granitos do complexo Echassières por Aubert (1969) e Kosakevith (1976), in Ohnenstetter \& Piantone (1988). O caso de Pitinga é o primeiro onde fica caracterizada a existência de fases minerais intermediárias entre o pirocloro primário e a fase final, a columbita. Embora o pirocloro tenha sido classificado em 3 variedades, não existe nenhuma descontinuidade composicional. $\mathrm{O}$ trend geoquímico da transformação é caracterizado por uma forte perda de $\mathrm{Pb}$ e enriquecimentos em U e, principalmente, $\mathrm{Nb}$. Não obstante as intensas substituições químicas, as transformações no pirocloro são do tipo displacive (Putnis 1995). Entretanto, a passagem de pirocloro para columbita implica uma transformação re- 
Tabela 4: Análises por microssonda eletrônica (WDS) em peso \% e fórmula estrutural da columbita na subfácies AGN do depósito criolítico pegmatóide.

\begin{tabular}{|c|c|c|c|c|c|c|c|c|}
\hline Local & \multicolumn{2}{|c|}{ Encaixante topo zona A } & \multicolumn{2}{|c|}{ Zona criolítica A } & \multicolumn{2}{|c|}{ Zona criolítica B } & \multicolumn{2}{|c|}{ Albita granito transicional } \\
\hline Subfácies & \multicolumn{2}{|c|}{$\mathrm{AGN}$} & \multicolumn{2}{|c|}{$\mathrm{AGN}$} & \multicolumn{2}{|c|}{$\mathrm{AGN}$} & \multicolumn{2}{|c|}{$\mathrm{AGT}$} \\
\hline Prof.(m) & $95,18 \mathrm{~m}$ & $95,18 \mathrm{~m}$ & 117,410 & 139,660 & 186,400 & 224,910 & $150,19 \mathrm{~m}$ & $150,19 \mathrm{~m}$ \\
\hline Pontos & L5D-C3 & L5D-D3 & L8C1B3 & $\mathrm{L} 12 \mathrm{C} 3 \mathrm{~B} 2$ & L19C2B3 & $\mathrm{L} 18 \mathrm{C} 2 \mathrm{~B} 1$ & L5A3 & L5A6 \\
\hline $\mathrm{Nb}_{2} \mathrm{O}_{5}$ & 62,87 & 61,94 & 69,00 & 67,66 & 62,04 & 68,99 & 71,56 & 58,63 \\
\hline $\mathrm{Ta}_{2} \mathrm{O}_{5}$ & 6,54 & 6,11 & 5,27 & 5,79 & 5,08 & 6,14 & 2,55 & 5,55 \\
\hline $\mathrm{SiO}_{2}$ & nd & nd & nd & nd & nd & nd & nd & nd \\
\hline $\mathrm{TiO}_{2}$ & 1,94 & 1,68 & 1,16 & 4,06 & 6,65 & 1,33 & 1,21 & 7,27 \\
\hline $\mathrm{ZrO}_{2}$ & 0,05 & 0,02 & 0,20 & 0,10 & 0,23 & 0,37 & 0,02 & nd \\
\hline $\mathrm{ThO}_{2}$ & nd & nd & nd & 0,19 & 0,32 & 0,21 & nd & 0,04 \\
\hline $\mathrm{UO}_{2}$ & 0,29 & 2,42 & 0,42 & 0,15 & 1,93 & nd & 1,03 & nd \\
\hline $\mathrm{Y}_{2} \mathrm{O}_{3}$ & 0,05 & nd & nd & nd & 0,16 & nd & nd & nd \\
\hline $\mathrm{La}_{2} \mathrm{O}_{3}$ & 0,07 & 0,30 & 0,14 & nd & 0,02 & nd & 0,09 & nd \\
\hline $\mathrm{Ce}_{2} \mathrm{O}_{3}$ & nd & nd & nd & nd & nd & nd & nd & nd \\
\hline $\mathrm{CaO}$ & 0,00 & 0,00 & nd & 0,01 & nd & 0,04 & 1,09 & 2,94 \\
\hline $\mathrm{MnO}$ & 7,35 & 7,72 & 10,07 & 7,93 & 6,09 & 3,82 & 7,97 & 3,85 \\
\hline $\mathrm{FeO}$ & 9,34 & 8,57 & 7,000 & 10,06 & 8,46 & 15,73 & 7,44 & 1,74 \\
\hline $\mathrm{Fe}_{2} \mathrm{O}_{3}$ & 2,51 & 2,30 & 4,17 & 1,55 & 5,24 & nd & 4,61 & 14,89 \\
\hline $\mathrm{SrO}$ & na & na & nd & nd & 0,01 & 0,07 & na & na \\
\hline $\mathrm{PbO}$ & nd & nd & nd & 0,60 & 0,29 & nd & nd & nd \\
\hline $\mathrm{Na}_{2} \mathrm{O}$ & nd & 0,08 & 0,01 & 0,03 & 0,09 & 0,01 & 0,03 & nd \\
\hline $\mathrm{K}_{2} \mathrm{O}$ & na & na & nd & 0,01 & nd & 0,02 & na & na \\
\hline $\mathrm{SnO}$ & 1,35 & 1,41 & na & na & na & na & 0,66 & 1,66 \\
\hline $\mathrm{WO}_{3}$ & 0,06 & 0,62 & na & na & na & na & 0,28 & 0,37 \\
\hline $\mathrm{Sb}_{2} \mathrm{O}_{5}$ & nd & nd & na & na & na & na & nd & nd \\
\hline $\mathrm{F}$ & 0,08 & 0,06 & nd & nd & 0,03 & 0,01 & 0,35 & 1,79 \\
\hline Total & 92,54 & 93,29 & 97,45 & 98,15 & 96,64 & 96,74 & 98,94 & 98,77 \\
\hline \multicolumn{9}{|c|}{ Fórmula estrutural calculada com base em 12 Cátions } \\
\hline $\mathrm{Fe}^{+2}$ & 1,930 & 1,790 & 1,360 & 1,940 & 1,630 & 3,120 & 1,420 & 0,320 \\
\hline $\mathrm{Fe}^{+3}$ & 0,520 & 0,480 & 0,810 & 0,300 & 1,010 & 0,000 & 0,880 & 2,740 \\
\hline $\mathrm{Mn}+2$ & 1,540 & 1,630 & 1,980 & 1,550 & 1,190 & 0,770 & 1,540 & 0,720 \\
\hline $\mathrm{Y}^{+3}$ & 0,010 & $*$ & $*$ & $*$ & 0,020 & $*$ & $*$ & $*$ \\
\hline $\mathrm{La}^{+3}$ & 0,010 & 0,030 & 0,010 & $*$ & $*$ & $*$ & 0,010 & $*$ \\
\hline $\mathrm{Ca}^{+2}$ & $*$ & $*$ & $*$ & $*$ & $*$ & 0,010 & 0,270 & 0,690 \\
\hline $\mathrm{Sr}^{+2}$ & $*$ & $*$ & * & $*$ & $*$ & 0,010 & $*$ & $*$ \\
\hline $\mathrm{Pb}^{+2}$ & * & * & $*$ & 0,040 & 0,020 & * & $*$ & $*$ \\
\hline $\mathrm{Na}^{+2}$ & * & 0,040 & $*$ & 0,010 & 0,040 & $*$ & 0,020 & $*$ \\
\hline $\mathrm{K}^{1+2}$ & $*$ & $*$ & $*$ & $*$ & $*$ & 0,010 & $*$ & $*$ \\
\hline $\mathrm{Th}^{+4}$ & $*$ & $*$ & $*$ & 0,010 & 0,020 & 0,010 & $*$ & $*$ \\
\hline Soma A & 4,010 & 3,970 & 4,160 & 3,850 & 3,930 & 3,930 & 4,140 & 4,470 \\
\hline $\mathrm{Nb}^{+5}$ & 7,030 & 6,980 & 7,250 & 7,060 & 6,470 & 7,400 & 7,370 & 5,830 \\
\hline $\mathrm{Ta}^{+5}$ & 0,440 & 0,410 & 0,330 & 0,360 & 0,320 & 0,400 & 0,160 & 0,330 \\
\hline $\mathrm{Ti}^{+4}$ & 0,360 & 0,320 & 0,200 & 0,700 & 1,150 & 0,240 & 0,210 & 1,200 \\
\hline $\mathrm{Zr}^{+4}$ & 0,020 & 0,130 & 0,020 & 0,010 & 0,030 & 0,040 & 0,050 & $*$ \\
\hline $\mathrm{U}^{+4}$ & 0,010 & $*$ & 0,020 & 0,010 & 0,100 & $*$ & $*$ & $*$ \\
\hline $\mathrm{Sn}^{+4}$ & 0,130 & 0,140 & $*$ & $*$ & $*$ & $*$ & 0,060 & 0,150 \\
\hline $\mathrm{W}^{+6}$ & nd & 0,040 & $*$ & $*$ & $*$ & $*$ & 0,020 & 0,020 \\
\hline Soma B & 7,990 & 8,020 & 7,820 & 8,140 & 8,070 & 8,080 & 7,870 & 7,530 \\
\hline Total & 12,000 & 11,990 & 11,980 & 11,990 & 12,000 & 12,010 & 12,010 & 12,000 \\
\hline
\end{tabular}

(AGN) albita granito de núcleo; (AGT) albita granito transicional; (na) não analisado; (nd) não detectado, $\left({ }^{*}\right)$ não calculado 


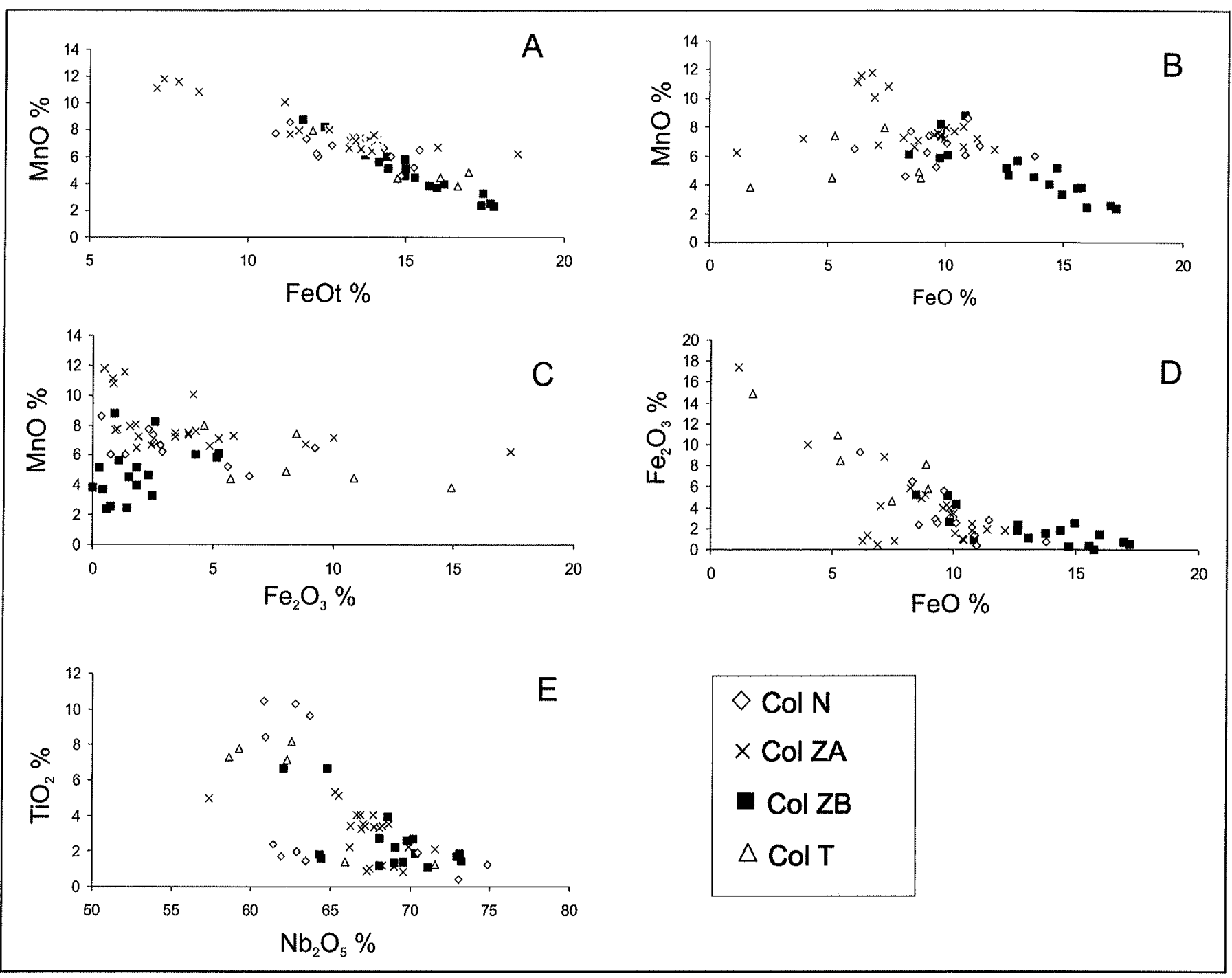

Figura 10 - Diagramas binários para a columbita de Pitinga. A: (Mn vs FeOt); B: (MnO vs $\mathrm{FeO}) ; \mathrm{C}:\left(\mathrm{MnO}\right.$ vs $\left.\mathrm{Fe}_{2} \mathrm{O}_{3}\right) ; \mathrm{D}_{2} \mathrm{Fe}_{2} \mathrm{O}_{3}$ vs $\mathrm{FeO}) ; \mathrm{E}:\left(\mathrm{TiO}_{2}\right.$ vs $\left.\mathrm{Nb}_{2} \mathrm{O}_{5}\right)$.

construtiva, pois o pirocloro possui um sítio hexacoordenado e outro octacoordenado, enquanto que a columbita tem dois sítios A e B hexacoordenados. A desestabilização da estrutura do pirocloro para formação da estrutura da columbita pode ter sido provocada pelo progressivo aumento do número de vacâncias no sítio A do pirocloro (Figura 11) ao longo das substitutições. $\mathrm{Na}$ Figura 11 observa-se como a concentração de $\mathrm{Nb}$ e o somatório de cátions no sítio A da columbita enquadram-se perfeitamente na evolução dos pirocloros.

Segundo Costi (2000), o autometassomatismo e a oxidação das bordas do corpo de albita granito teriam originado o AGB. A zonação da mineralização de $\mathrm{Nb}$ e Ta do granito Madeira (pirocloro no AGN e columbita no AGB) seria, portanto, consequiência destes processos na borda do corpo. No presente trabalho, verifica-se um quadro bem mais complexo. A columbita ocorre também no AGN. Petrograficamente, é nítida a alteração do pirocloro em contato com a criolita e a albita. Espacialmente, a distribuição desta columbita e a distribuição das variedades de pirocloro são estreitamente relacionadas ao DCM. Esta columbita é muito mais abundante em profundidade, junto às zonas criolíticas, mais especialmente na zona $\mathrm{B}$, a mais profunda, e onde a razão $\mathrm{FeO} / \mathrm{Fe}_{2} \mathrm{O}_{3}$ na columbita demonstra a formação deste mineral em ambiente relativamente mais redutor. Por outro lado, as variações desta razão na columbita marcam cla- ramente a passagem gradual para um ambiente mais oxidante com a diminuição da profundidade; neste sentido observa-se a presença de correlação $\mathrm{FeO} v s \cdot \mathrm{Fe}_{2} \mathrm{O}_{3}$ já na columbita da zona criolítica A. Caracteriza-se, portanto, a formação de columbita a partir da alteração do pirocloro primário pelo fluido responsável pela formação do DCM.

A presença de columbita de formação ligada ao DCM não contradiz o modelo de Costi (2000) de formação do AGB a partir da oxidação do AGN. Na realidade, no presente trabalho demonstra-se, inclusive, que a columbita da subfacies transicional é a mais oxidada de todas as aqui estudadas. Entretanto, o ABN e o AGB têm algumas diferenças nas suas paragêneses que não podem ser explicadas apenas pelo modelo de Costi (op. cit.). Um exemplo é o fato da criolita disseminada ocorrer apenas no AGN, enquanto que no AGB ocorre apenas fluorita disseminada e em quantidades muito menores do que a primeira. Neste sentido, chamam atenção as descontinuidades nas evoluções geoquímicas no pirocloro (Figuras $7 \mathrm{e}, \mathrm{f}, \mathrm{g}, \mathrm{h}, \mathrm{i}$ ), constatadas na subfácies transicional. Nesta subfácies, são marcantes o empobrecimento do pirocloro em $\mathrm{F}$ e o seu enriquecimento em $\mathrm{FeOt}$. Como se trata de mineral portador de hidroxila, é possível que o comportamento contrário destes dois elementos seja acentuado no pirocloro pelo efeito F-Fe-avoidance (Munoz 1984). Por outro lado, as concentrações de elementos compatíveis com o 


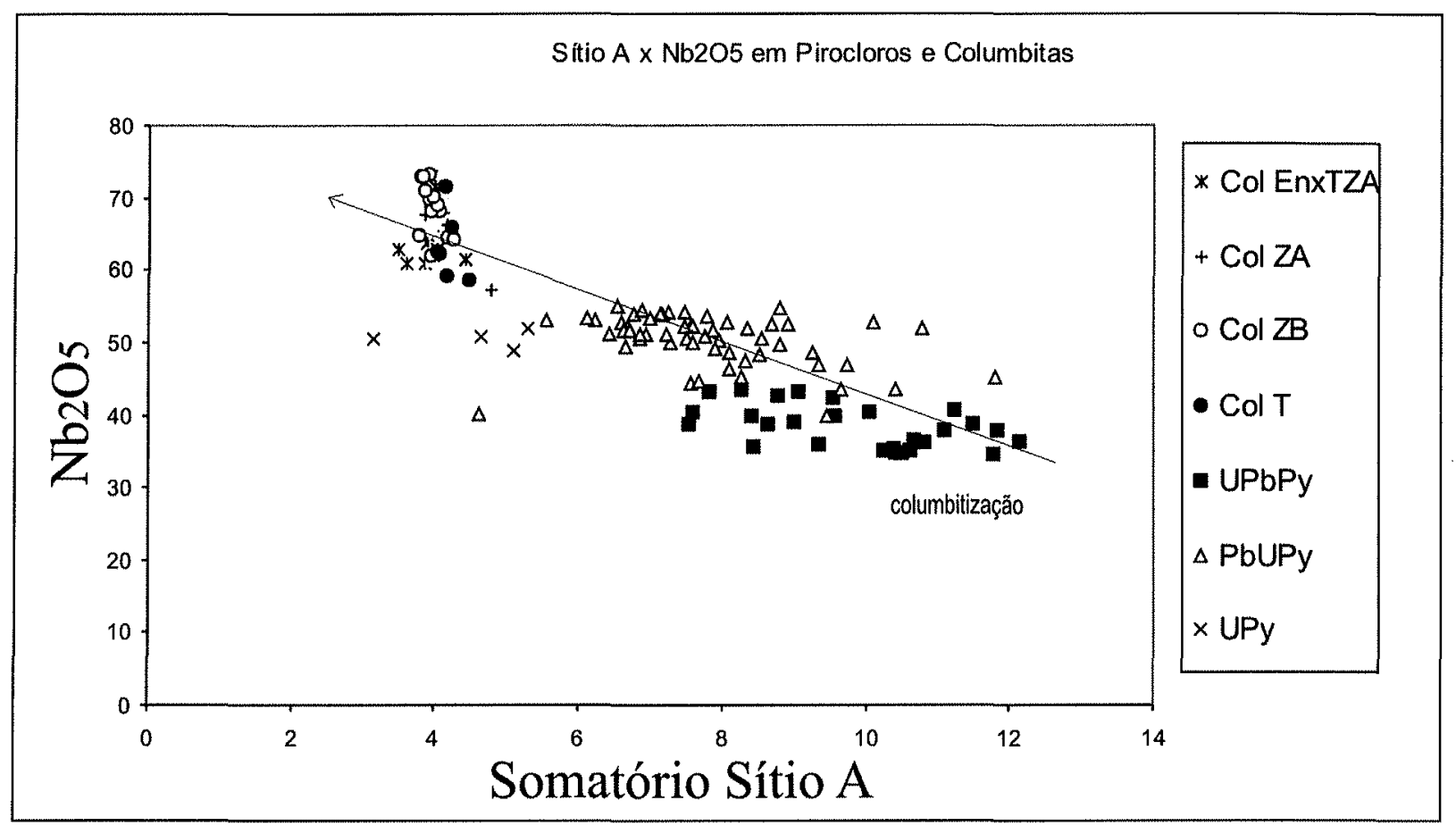

Figura 11: Correlação entre o somatório de cátions do sítio $\mathrm{A}$ e a concentração de $\mathrm{Nb}_{2} \mathrm{O}_{5}$ no processo de columbitização do pirocloro do albita granito.

F, e usualmente transportados em complexos fluorados, como o $\mathrm{Ce}$, Sn e Ca, diminuem acentuadamente em paralelo ao empobrecimento daquele elemento no pirocloro da subfácies de transição. Há que se suspeitar, portanto, que a descontinuidade nas evoluções geoquímicas no pirocloro possa ser ligada a uma diminuição na atividade de $\mathrm{F}$ na solução à medida que se afasta do DCM. Assim, o limite entre o AGN e o AGB não corresponderia apenas a um limite entre zona não oxidada e zona oxidada, respectivamente, por efeito de localização na cúpula/borda do corpo ou ação de fluidos da encaixante. Ele representa, essencialmente, uma mudança nas condições físico-químicas de um fluido ascendente, redutor e rico em F. Fluido este que, depletado em F pela deposição de criolita, passou a depositar fluorita nas partes mais distantes de seu ponto de aporte, a área central do AGN, onde localiza-se o DCM.

A columbitização do pirocloro acarretou, especialmente nas porções mais profundas do DCM, a liberação de quantidade considerável de U não incorporado na estrutura da columbita. Acredita-se aqui que fases minerais neoformadas, como a uraninita, a uranotorita e o silicato de urânio, identificadas por Lenharo (1998), possam ter sido formadas com o $U$ assim disponibilizado. Observa-se que não ocorrem correlações significativas do $\mathrm{UO}_{2}$ com outros óxidos, o que indica que este elemento tem um comportamento geoquímico mais complexo que, talvez, esteja relacionado aos diferentes graus de oxidação pois, excetuando a zona transicional, seus teores são relativamente reduzidos nas zonas menos oxidadas. Parte da galena encontrada na mina Pitinga também deve ter origem associada à liberação do $\mathrm{Pb}$ do pirocloro.

CONCLUSÕES E RECOMENDAÇÕES Os modelos genéticos em discussão para o minério primário da serra do Madeira são o metassomático, inicialmente definido por Horbe et al. $(1985,1991) \mathrm{e}$ Teixeira et al. (1992), que associaram a mineralização à formação de um apogranito, e o modelo magmático defendido por Lenharo (1998) e Costi (2000) que consideram o albita granito uma rocha magmática, bem como as mineralizações associadas.
Este estudo revela que a mineralização de $\mathrm{Nb}$ e Ta do albita granito da mina Pitinga teve uma evolução bastante mais complexa do que o anteriormente suposto. Esta iniciou-se em ambiente magmático, com a formação de uma variedade rara de pirocloro, o U-Pb-pirocloro, bastante rico em $\mathrm{Sn}$, outro aspecto composicional incomum para este mineral, mas perfeitamente coerente com a presença de cassiterita magmática, formadora de um depósito de classe mundial.

O pirocloro primário foi afetado por columbitização caracterizada, num estágio inicial, pela perda de $\mathrm{Pb}$ e enriquecimento em $\mathrm{U}$ e $\mathrm{Nb}$ dando origem a uma série contínua de composições, passando pelo $\mathrm{Pb}$-U-pirocloro até o U-pirocloro. Ao longo desta evolução, ocorreu um aumento constante na vacância do sítio A, que foi, muito provavelmente, o responsável pela desestabilização da estrutura do pirocloro, resultando na formação de columbita. Esta apresenta algumas características composicionais relativamente raras, como as altas concentrações de Sn e U, herdadas do pirocloro, e de $\mathrm{Fe}^{3+}$.

Nos pirocloros, paralelamente ao empobrecimento em $\mathrm{Pb}$ ocorrem o enriquecimento em $\mathrm{Ca}, \mathrm{F}, \mathrm{Ce}$ e $\mathrm{Sn}$ e o empobrecimento em $\mathrm{Fe}$. Na zona de transição entre o $\mathrm{AGN}$ e o AGB ocorre, entretanto, uma inversão nestas evoluções, o que é interpretada como fruto da diminuição da atividade de flúor no fluido responsável pela columbitização. A columbita apresenta uma variação na razão $\mathrm{FeO} / \mathrm{Fe}_{2} \mathrm{O}_{3}$ que, aparentemente, também relaciona-se espacialmente ao DCM, indicando gradientes nas condições de oxi-redução do fluido responsável pela formação deste depósito.

As relações observadas em lâmina petrográfica, a distribuição espacial das variedades de pirocloro e suas evoluções geoquímicas e a distribuição espacial das variações composicionais da columbita, levam a crer que a columbitização do pirocloro foi promovida pelo mesmo fluido responsável pela mineralização criolítica, cujo aporte ascendente ocorreu pela zona central do albita granito, onde localiza-se o DCM. A diminuição gradual da atividade de $\mathrm{F}$, com o afastamento da zona de aporte e empobrecimento neste elemento pela deposição da 
criolita disseminada, gerou os gradientes e as descontinuidades geoquímicas observadas nos minerais estudados, assim como, provavelmente, algumas das diferenças entre as paragêneses do AGN e o AGB. Possivelmente, outros minerais da paragênese secundária formaram-se sob influência, direta ou indireta, da columbitização, como deve ser o caso de minerais de U que utilizaram o excesso deste elemento, que não foi incorporado na estrutura da columbita, ou de minerais de $\mathrm{Pb}$, como a galena.

Os resultados obtidos mostram que o minério de $\mathrm{Nb}$ e $\mathrm{Ta}$ apresenta importantes variações composicionais que influenciam diretamente seu beneficiamento. Por exemplo, a alteração do pirocloro gerou neste mineral, assim como na columbita a partir dele formada, uma película rica em $\mathrm{Fe}$ que, certamente, acarreta efeitos que precisam ser bem caracterizados para se chegar ao melhor rendimento da flotação e separação magnética. Por outro lado, as importantes variações composicionais encontradas implicam consideráveis diferenças de densidade que também influenciam na eficiência do beneficiamento. Por outro lado, evidenciou-se que as variações no minério possuem um zoneamento espacial na escala do albita granito. Assim, acredita-se que o prosseguimento deste estudo com um número maior de amostras deverá produzir resultados fundamentais para a otimização da lavra e beneficiamento do minério de $\mathrm{Nb}$ e Ta do albita granito, que ora se inicia. Finalmente, do ponto de vista de detalhamento da columbitização, cabe ressaltar que uma grande contribuição poderia ser obtida com o emprego de microscópio eletrônico de transmissão.

Agradecimentos $\mathrm{O}$ trabalho foi desenvolvido no quadro do subprojeto "Alvo Criolita de Pitinga", que faz parte do projeto "Caracterização de Depósitos Minerais em Distritos Mineiros da Amazônia", cuja execução foi apoiada pela Agência Financiadora de Estudos e Projetos (FINEP), através de uma cooperação entre a Mineração Taboca Ltda., o Departamento Nacional da Produção Mineral (DNPM) e a Agência para o Desenvolvimento Tecnológico da Indústria Mineral do Brasil (ADIMB). Os autores agradecem aos revisores elas críticas e sugestões

\section{Referências}

Almeida F.F.M., Hasui Y., Brito Neves B.B., Fuck R.A. 1981. Brazilian structural Provinces. An introduction: Earth Sci. Rev., 17:1-29.

Barker W.W., White P.S. \& Knop O. 1976. Pyrochlores. X. Madelung energies of pyrochlores and defect fluorites. Can. J. Chem., 54:2316-2334.

Chakoumakos B.C. 1984. Systematics of the pyrochlore structure type, Ideal A2B2X6Y. Journal of Solid State Chemistry, 53:120-129.

Chakoumakos B.C. \& Ewing R.C. 1985. Crystal chemical constraints of the formation of actinide pyrochlores. In: C.M. Jantzen. J.A. Stone, R.C. Ewing (eds.) Scientific Basis of Nuclear Waste Management VIII, Material Research Society, Pittsburgh, pp. 641-646.

Costi H.T. 2000. Petrologia de granitos alcalinos com alto fuior mineralizados em metais raros: o exemplo do Albita granito da Mina Pitinga, Amazonas, Brasil. Tese de Doutoramento, Centro de Geociências, UFPa, 345p.

Ercit T.S. 1994. The geochemistry and crystal chemistry of columbitegroup minerals from granitic pegmatites, southwestern Grenville Province, Canadian Shield. The Canadian Mineral., 32:421-438.

Ercit T.S., Hawthorne F.C., Cerny P. 1994. The structural chemistry of Kalipyrochlore, a "Hydropyrochlore". The Canadian Mineral., 32:415-420.

Gibbs A. K. \& Barron C.N.. 1983. The Guiana Shield Reviewed. Episodes, 6:7-14.

Hodgson N.A. \& Le Bas M.J. 1992. The Geochemistry and Cryptic Zonation of Pyrochlore from San Vicente, Cape Verde Islands. Mineral. Mag., 56:201-214.

Hogarth D.D. 1977. Classification and nomenclature of the pyrochlore group. Am. Mineral., 62:403-410.

Horbe M.A., Horbe A.C., Costi H.T., Teixeira J.T. 1991. Geochemical characteristics of cryolite-tin-bearing granites from the Pitinga mine, northwestern Brazil. J. Geoch. Explor. 40:227-249,

Horbe M.A., Horbe A.C., Teixeira J.T., Costi H.T. 1985. Granito Madeira: petrologia, petroquímica e mineralizações. In: SBG, Simp. Geol. Amazônia, 2, Belém. Anais, SBG, p. 284-320.

Lenharo S.L.R. 1998. Evalução magmática e modelo metalogenético dos granitos mineralizados da região de Pitinga, Amazonas, Brasil. Tese de Doutoramento, Universidade de São Paulo, 290p.

Lumpkin G.R. \& Ewing C.R. 1988. Alpha-decay damage in minerals of the pyrochlore group. Phys. Chem. Minerals, 16:2-20.

Lumpkin G.R. \& Ewing C.R. 1992. Geochemical alteration of pyrochlore group minerals: microlite subgroup. Am. Mineral., 77:179-188.

Moreau J. \& Tramasure G. 1964. Estude de composes synthetiques de la famille des columbite - tantalite et tapiolite - mossite. Compte Rendus Hebdomadaires des Seances de l Academie des Sciences, 9:2599-2601

Munoz J.L. 1984. F-OH and Cl-OH exchange in micas with application to hydrothermal ore deposits. In: Micas, Mineralogycal Soc. Am. Reviews in Mineralogy, 13:469-493.

Ohnenstetter D. \& Piantone P. 1988. Geochimie et evolutions des mineraux du groupe des columbo-tantalites et des mineraux du groupe du pyrochlore du sondage GPF I Echassieres (Allier). Doc. Bureau de Recherches Geologiques et Minieres, (BRGM). Paris, France, $\mathrm{N}^{\circ}$ 124. Pages 113-250.

Pereira V.P. 1995. A alteração no Maciço Alcalino-carbonatitico de Catalão I-Brasil. Evolução mineralógica. Tese de Doutoramento, Universidade Federal do Rio Grande do Sul, Brasil/Université de Poitiers, França, $279 \mathrm{p}$.

Putnis A. 1992. An Introduction to Mineral Sciences. Cambridge University Press, Cambridge, $457 \mathrm{p}$.

Santos J.O.S., Hartmann L.A., Gaudette H.E., Groves D.I., Mcnaughton N.J., Fletcher I.R. 2000. A new understanding of the provinces of the Amazon Craton based on integration of field mapping and U-Pb and Sm-Nd geochronology. Gondw. Res, 3:453-488.

Schobbenhaus C., Hoppe A., Lork A., Baumann A. 1994. Idade do magmatismo Uatumã no norte do Cráton Amazônico, Escudo das Guianas (Brasil) - primeiros resultados. In: SBG, Congr. Bras. Geol., 38. Camboriú. Anais, v.2, p. 395-397.

Shanon R.D. 1976. Revised effective ionic radii and systematic studies of interatomic distances in halides and chalcogenides. Acta Crystallogr., A32:751-767.

Tassinari C.C.G., Bettencourt J.S., Geraldes M.C., Macambira M.J.B., Lafon J.M. 2000. The Amazonian Craton. In: U.G. Cordani, A. Thomas Filho, J. Milani (org.) Tectonic Evolution of Southamerica. Rio de Janeiro, CPRM, p. 41-95.

Teixeira J.T, Costi H.T., Minuzzi O.R.R., Soares E.A.A. 1992. Depósitos primários de criolita, cassiterita, xenotímio e columbita em apogranito - mina do Pitinga (AM). In: SBG, Congr. Brás. Geol., 37 São Paulo, Anais, v.l, p.: 212-213.

Van der Veen, A. H. 1963. A study of pyrochlore. Verhandelingen van het Koninklijk Nederlands geologisch mijnbouwkundig genootschap. Geologische Serie, v. 22, 188 p.

Manuscrito A-1617b Revisão aceita em 30 de agosto de 2006 